\title{
Supporting Preprimary Parent Engagement in South Sudan
}

LESSONS FROM EIGHT PARENT EDUCATION PROGRAMS

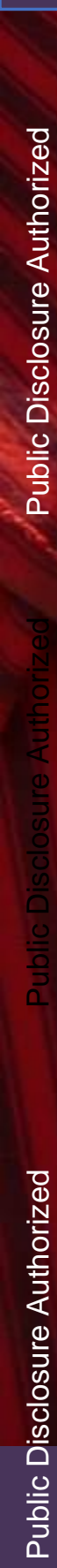

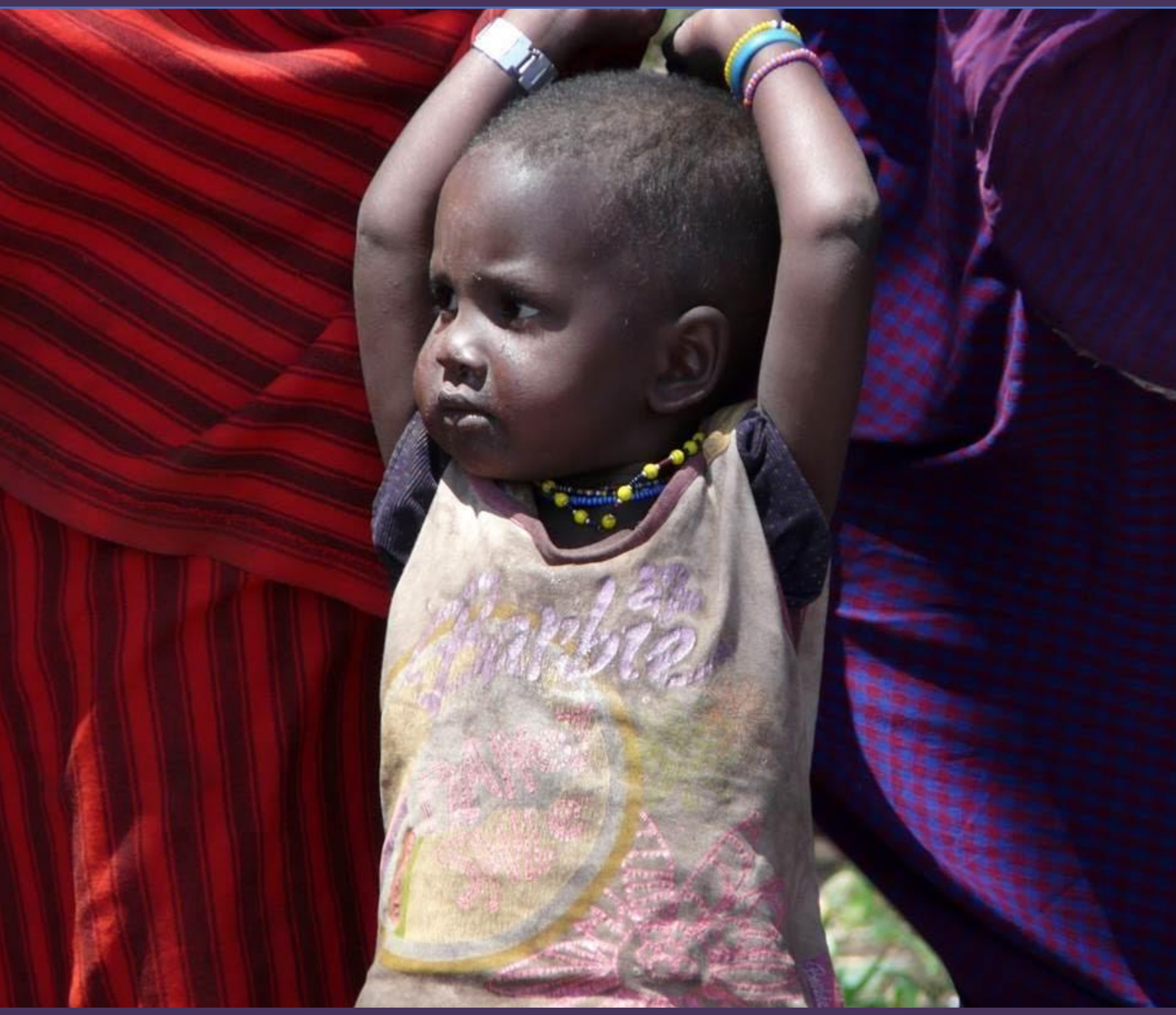

(4) WORLD bank Group

June 29, 2020 


\section{About this document:}

An early childhood diagnostic survey conducted in South Sudan by the World Bank and UNICEF in 2019 recommended that engagement of parents and communities be leveraged to increase early learning opportunities for the youngest children in this unique and challenging context. Following this recommendation, the World Bank began engagement with the Ministry of General Education and Instruction (MoGEI) towards the development of a parenting program specific to the context of South Sudan.

This document, a review of preprimary parenting programs implemented in different contexts, represents the first of a three-step process towards the design of a program for South Sudan. The second step will involve in-depth, qualitative study of caregiving practices for preprimary children in South Sudan, providing vital information around local customs and beliefs that can be built into the program. These first two steps will inform the initial design of a context-specific preprimary parenting program. In the third and final step, the program will be piloted with parents in South Sudan and feedback from participants and other key stakeholders will be used to refine the content and delivery of the program.

In addition to this review, the project will produce the following interrealated outputs: (i) a report highlighting caregiving practices for preprimary children in South Sudan, (ii) a draft pre-primary parenting program for South Sudan with facilitator guide and accompanying materials and (iii) a report documenting the process of creating this context specific parenting program in order to support simliar efforts elsewhere. 


\section{Acknowledgements}

This report has been prepared by Saima S. Malik (Former Education Consultant, World Bank) and Sharanya Ramesh Vasudevan (Education Consultant, World Bank) with contributions and support from Hongyu Yang (Task Team Leader, Senior Education Specialist, HAFE1). The team is grateful for the guidance and continued support from Husam Abudagga (Country Manager, AFMJB), Anne Margreth Bakilana (Program Leader, HAFED1), Safaa El Tayeb El-Kogali (Practice Manager, HAFE1), Victoria Gyllerup (Operations Adviser, AFRDE), and Rosario Aristorenas (Senior Program Assistant, HAFE1).

The team is also grateful for contributions from Huma Kidwai, Ella Victoria Humphry, Samira Halabi, and Owen Ozier who served as peer reviewers. Additionally, the team would like to thank World Bank colleagues in the country office - Charles Joachim Bagaza, and Joyce Wani Gamba - for their support and collaboration. 


\section{Acronyms}

$\begin{array}{ll}\text { CCD } & \text { Care for Child Development } \\ \text { CEI } & \text { Center for Education Innovations } \\ \text { ECCE } & \text { Early Childhood Care and Education } \\ \text { ECD } & \text { Early Childhood Development } \\ \text { ECPC } & \text { Early Child Peace Consortium } \\ \text { ELMI } & \text { Emergent Literacy and Math Initiative } \\ \text { FCV } & \text { Fragility, Conflict, Violence } \\ \text { GES } & \text { Ghana Education Services } \\ \text { IDELA } & \text { International Development and Early Learning Assessment } \\ \text { IDP } & \text { Internally Displaced People } \\ \text { MOGEI } & \text { Ministry of General Education and Instruction } \\ \text { MOECP } & \text { Mother Child Education Program } \\ \text { NYU } & \text { New York University } \\ \text { RCT } & \text { Randomized Control Trial } \\ \text { SDQ } & \text { Strengths and Difficulties Questionnaire } \\ \text { TEEP } & \text { Turkey Early Enrichment Project }\end{array}$




\section{Contents}

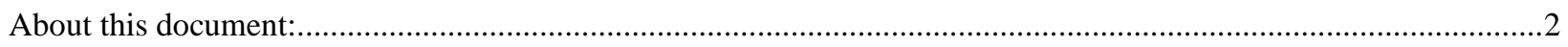

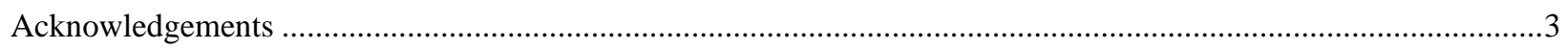

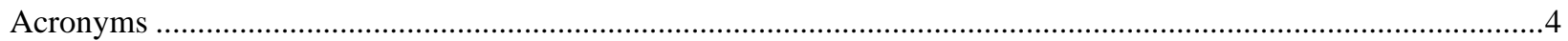

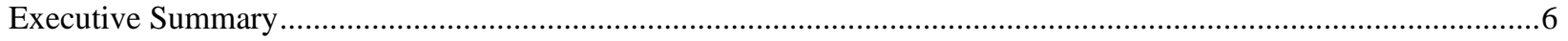

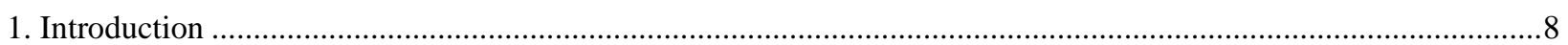

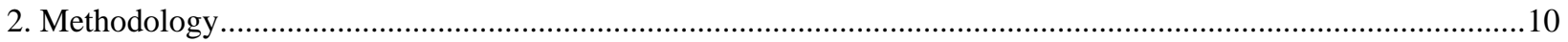

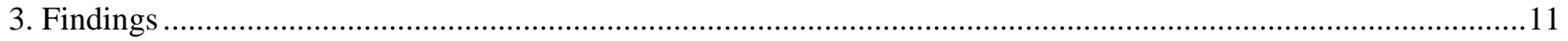

3.1 Lessons from parent engagement in early childhood .................................................................. 11

3.2 Lessons from eight parent education programs ...........................................................................

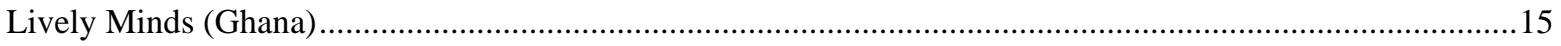

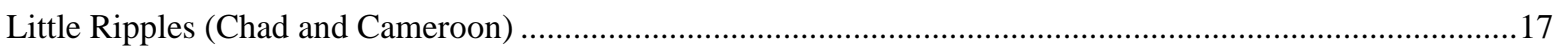

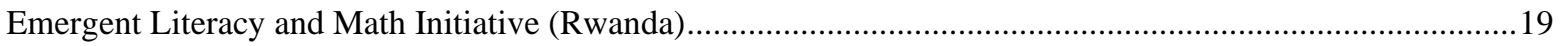

Mother Child Education Program (Turkey) ……….............................................................................21

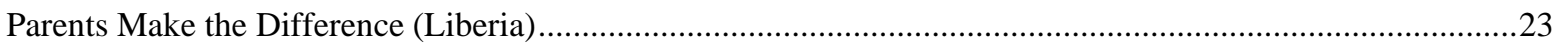

Literacy Boost Community Action (Rwanda) ………...............................................................................25

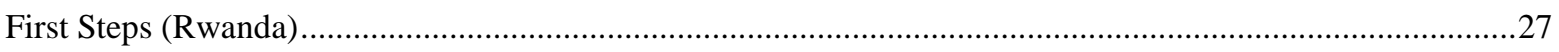

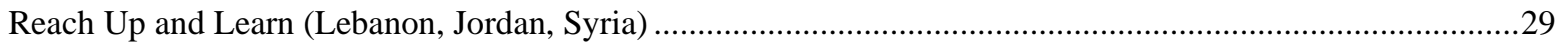

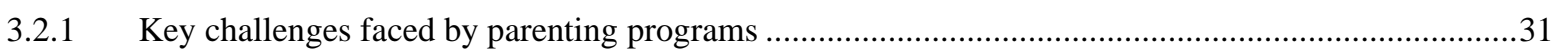

4. Key considerations for designing a preprimary parenting program in South Sudan .............................................36

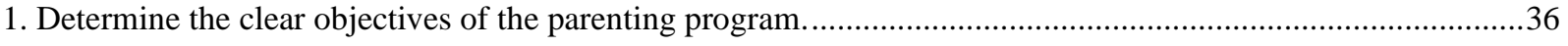

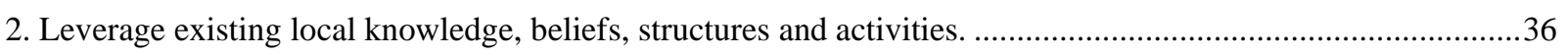

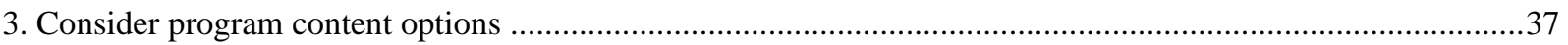

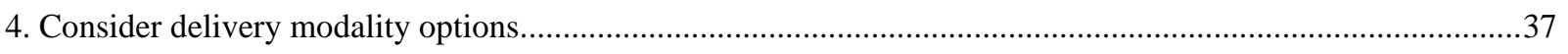

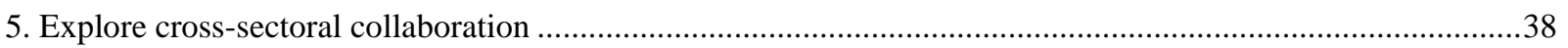

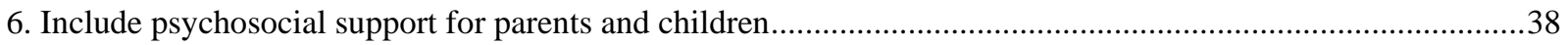

7. Provide ongoing support to facilitators and feedback to parent participants.....................................................39

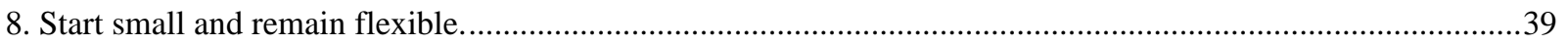

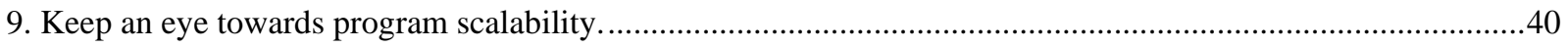

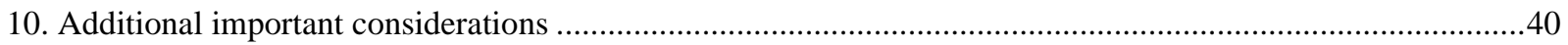

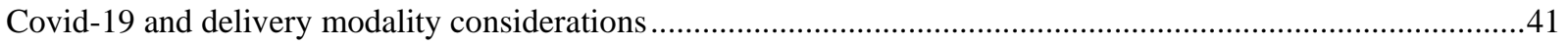

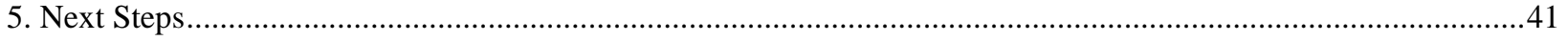

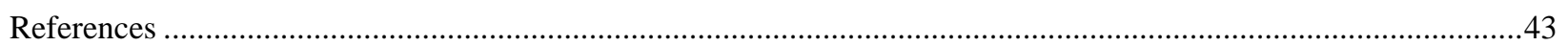

Annex 1. South Sudan Parent Workshop Draft ...............................................................................................48

Annex 2. Sample Session Outline ................................................................................................................. 


\section{Executive Summary}

This literature review aims to understand the design and content of successful preprimary parenting programs specifically those implemented in fragile, conflict and violent contexts. This document serves as a resource guide for the creation of a preprimary parenting program for the South Sudanese context, to enhance school readiness of children between the ages of 3-5 years through basic literacy, numeracy and socio emotional skills.

Parent engagement is seen as an essential component of high quality ECD/ECE programs. Parents and caregivers are the "first educators" in a child's life and the creation and implementation of programs that empower them, irrespective of their own educational backgrounds, is important. Studies show that the interactions children have with their parents and other primary caregivers can deeply influence emergent literacy, numeracy and socio-emotional skills. The importance of positive parenting and caregiving practices is perhaps most pronounced in contexts where access to and participation in high quality preprimary services is limited.

Places where young children, their families and communities face fragility, conflict and/or violence (FCV) present additional challenges. The effects of fragility, conflict and violence have shown to have long term effects on children. Research shows that in fragile contexts, large numbers of young children remain out of school due to lack of safe spaces, low number of qualified teachers and little to no learning materials. These factors also inhibit children's enrolment and participation in preprimary education in South Sudan.

This paper provides a brief overview of the benefits of parent engagement early in life and explores eight parenting programs whose design and implementation could be useful to increase the engagement of parents in preprimary skill development in South Sudan. Bearing in mind the context of South Sudan, five key criteria that guided selection of the programs included: (i) low cost of implementation, (ii) use of local resources, (iii) creation of contextually relevant curriculum, (iv) supporting parents who do not know how to read/write, and (v) evidence of benefits following empirical testing. Following this selection criteria, the programs reviewed include: The Lively Minds program in Ghana; the Little Ripples program in Chad and Cameroon; the Early Literacy and Math Initiative in Rwanda, the Mother Child Education program in Turkey; the First Steps, program in Rwanda, the Literacy Boost program's Community Action component in Rwanda; the Parents Make the Difference Program in Liberia and the Reach Up and Learn program in Jordan, Syria and Lebanon. In addition to discussing successes, this desk review highlights key challenges faced by these programs as potential problems to be anticipated and mitigated early on in the development of a similar program in South Sudan.

This review presents key considerations in the design of a preprimary parenting program in South Sudan. These are:

1. Determine clear objectives for the parenting program

2. Leverage existing local knowledge, beliefs, structures and activities

3. Consider mode of program delivery

4. Consider program content

5. Provide ongoing support to program facilitators and feedback to parent participants

6. Start small and remain flexible

7. Consider engaging youth

8. Explore how to engage fathers

Special considerations related to the current context of the global COVID-19 crisis are also discussed. 
It is important to have a clear picture of the lived experience of young children, their families and communities in South Sudan prior to designing a program that is relevant and appropriately meets their needs. This will include an understanding of the local customs and traditions used in caregiving of the youngest children (such as which songs, stories and games are commonly shared), how much interaction fathers and mothers have with their young children, when the engagement occurs and the nature of engagement, resources readily available on the ground to use in teaching and learning (e.g. sticks, rocks, plants, fabric), daily activities of families (to ascertain moments and activities that lend themselves to teaching and learning), local perceptions around child development and early parenting, teaching and learning, and caregivers perceptions around key opportunities and challenges in supporting children's cognitive, physical and socio-emotional skills and school readiness. It will be especially important, in the context of the current covid-19 crisis, to get a sense of alternative delivery modalities to engage parents in South Sudan in the immediate future. A key next step should involve the design of focus group discussion and key informant interview questions and protocols for the qualitative study. Information gathered in this review may serve as a guide in determining those questions and protocols. 


\section{Introduction}

An essential aspect of early stimulation is ongoing, attentive, and responsive interaction between the caregiver and the child (Early Child Peace Consortium, 2018). While teachers and school leaders play an important role in providing preprimary education services, parents and caregivers play a large role in creating a safe environment that stimulates and enriches their children's lives (ECPC, 2018). A wide body of research suggests that the quality of parent-child interactions during early years is strongly associated with long term gains in the development of emergent reading skills including oral language development, vocabulary, and letter-word knowledge as well as emotional regulation skills (Chazan-Cohen, Raikes, Brooks-Gunn, Ayoub, Pan, Kisker, \& Fuligni, 2009). Findings on the effectiveness of parenting programs in Ethiopia and Jordan showed that flexibly scheduled parenting programs significantly increase caregivers' knowledge of child development and activity engagement (Al-Hassan and Lansford, 2011) and improved children's learning and development across emergent literacy and math domains. Further, parent engagement early on in life has been found to have a long lasting impact on children's lives: a study examining the impact of parent engagement interventions in Jamaica (Gertler, Heckman, Pinto, Zanolini, Vermeerch, Walker, \& Grantham-McGregor, 2013) found that 19 and 20 years later, children of mothers receiving training on stimulating and responsive play achieved higher levels of educational attainment and earned more money than comparison groups.

Multiple delivery channels may be employed to raise awareness around the importance of early stimulation and promote strong physical, socio-emotional and cognitive development of the youngest children. Families may be reached individually through home visits or collectively in group sessions. These delivery channels are important especially in contexts of fragility, conflict or violence (FCV), where the engagement of children in formal pre-primary services are low due to a lack of resources, high mobility and high illiteracy rates and where governments may not be able to support effective education systems and preprimary programs are not adequately funded as resources are usually directed elsewhere (Burde, Guven, Kelcey, Lahmann, \& Al-Abbadi, 2015).

This is the case in South Sudan, where only about $8 \%$ of children are enrolled in preprimary education. The majority of children do not have access to pre-primary services due to a lack of provision, high mobility (about half the population moving as pastoralists or IDPs), lack of awareness around the importance of pre-primary education and low parental literacy in the country (73\% illiteracy rate). Additionally, similar to other FCV contexts that are characterized by an inflow of humanitarian aid, the education sector often receives less funding as compared to the health, food security and water/sanitation sectors (Malik, 2019). In South Sudan this translates to the education sector receiving about 46 million USD from a 1.72 billion USD appeal (Malik, 2019).

In the absence of effective and safe schooling systems, it is usually the family who emerge to build a protective learning environment for their children (ECPC, 2018). In countries like South Sudan, where literacy levels are low and access to formal preprimary schooling is scarce, it becomes even more important to explore avenues of engagement at the family and community level to support the foundational learning of children. Research conducted in other countries in the region show that despite low literacy levels amongst parents, they can effectively contribute to building their child's school readiness in pre-numeracy, pre-literacy and socio emotional skills (Malik, 2019). Exploring ways to leverage the strength of South Sudanese families and communities in early childhood education was one of the key recommendations emerging from a stakeholder consultation workshop conducted in South Sudan in 2019 that involved policy makers, teachers, parents and development partners active in ECD in the country. 
This paper provides a brief overview of existing literature on the benefits of parent engagement early in life and explores eight parenting programs that have been designed and implemented in Ghana, Chad, Cameroon, Rwanda, Liberia, Syria, Jordan and Lebanon to boost parent engagement in the lives of their young children. By doing this, the paper aims to create a resource document that can inform the development of a context-specific parenting program model for South Sudan. 


\section{Methodology}

The literature review provides an overview of the vast body of literature highlighting the positive association of parental engagement and children's early skill development. It examines eight parent ${ }^{1}$ engagement programs that have demonstrated positive outcomes in various contexts. Reflecting on both of these sources, the review provides key considerations for the development of a preprimary parent engagement program in South Sudan and discusses next steps towards this objective.

As it was important to include a variety of sources in the review, academic articles were supplemented with reports produced by organizations (including the World Bank, Save the Children and UNICEF) and country reports. These documents (including country partnership frameworks and country diagnostic reports) were extremely useful in understanding how different countries recruit, train and support preprimary education providers.

In addition to academic articles, over forty sources helped to review a total of eight parenting programs included in this document. These include the Lively Minds program in Ghana, the Mother Child Education program in Turkey, the Little Ripples program in Chad and Cameroon, First Steps, Early Literacy and Math Initiative, and Literacy Boost's Community Action Component in Rwanda, Parents Make the Difference Program in Liberia and Reach Up and Learn in Syria, Jordan and Lebanon. Given the challenges associated with low-resource availability in South Sudan, five key factors guided the selection of programs to be reviewed here. These included:

- Low cost of implementation

- Use of local resources

- Creation of contextually relevant curriculum

- Supporting parents who do not know how to read and write

- Evidence of benefits following empirical testing.

\footnotetext{
${ }^{1}$ While dialogue and program has focused mostly on the parents of the child, most literature and programs reviewed indicate that a child's earliest experiences are profoundly impacted by many individuals in their homes and communities (including siblings, grandparents, neighbors and friends) other than biological parents. Since more programs reviewed use the word parent, we use the same term for simplicity in this document but acknowledge the role of all caregivers of the young child and advocate for inclusion of these important individuals into programming efforts as indicated in the final section of this document.
} 


\section{Findings}

\subsection{Lessons from parent engagement in early childhood}

The parents of young children bear the responsibility of providing a home environment conducive to the successful attainment of foundational skills. For instance, a vast body of research has linked literacy-related features of the child's home environment to successful acquisition of literacy and language skills (Friedlander, 2015; Christian, Morrison, \& Bryant, 1998; Lonigan, Dyer \& Anthony, 1996; Purcell-Gates, 1996; Sénéchal, LeFevre, Hudson, \& Lawson, 1996; Payne, Whitehurst \& Angell, 1994; Crain-Thorenson \& Dale, 1992; Dickinson \& Tabors, 1991; Snow et al., 1991; Teale, 1986; Wells, 1985; Hess \& Holloway, 1984). These features include the presence of reading materials (e.g., books, magazines and newspapers) in the home and the practice of literacy activities (e.g., reading together, playing together, singing songs and having rich conversations) by the child and her family. Engaging in literacy activities such as reading storybooks or playing with print material as a source of entertainment has been found to be predictive of early literacy competence in pre-kindergarten and kindergarten-age children (Sonnenschien, Baker, Serpell, Scher, Truitt, \& Munsterman, 1997). By sharing books, singing songs, and drawing pictures with their children, parents provide direct literacy and language experiences to their child (Snow, Burns \& Griffin, 1998). Similarly, verbal interaction between parents and children appears to be strongly linked to early language and literacy development. A review of the literature by Snow et al. (1998) found a consistently strong and positive relationship between the amount of talk between parents and young children and children's literacy skills later on. Similarly, Dodici, Draper, and Peterson (2003) found that verbal interaction between parents and children at 14, 24, and 36 months of age significantly predicted phonemic awareness, receptive vocabulary, symbolic representation, and early literacy skills at the beginning of school.

The link between a child's early home environment and later academic outcomes has been found to hold in various contexts throughout the world (Friedlander \& Goldenberg, 2016; Park, 2008; Wagner \& Spratt, 1988; Thorndike, 1976). Early on, Thorndike (1976) examined reading comprehension in 15 countries and found that family SES and availability of print material in the home predicted reading achievement among children. Hyunjooh Park (2008) compared data for grade 4 students from the Progress in International Reading Literacy Study (PIRLS) across 25 countries and learned that early home literacy activities, parental attitudes towards reading, and number of books at home positively affected children's reading performance (to varying degrees) in almost all countries. Friedlander and Goldenberg (2016) found that pairing teacher training with parent and community engagement activities in rural Rwanda produced higher literacy gains for primary school children. Malik et al. (2015) found that reading at home had a strong impact on reading frequency and fluency for rural Rwandan children in grades 2 and 3. As a result, the authors recommended intensifying efforts at engaging parents and ensuring that parents were made aware of how to encourage their children to read at home. Five years of programming that supported parent and community engagement in children's early learning led Save the Children International in Rwanda to conclude that: (i) parent support of children's early development boosts gains in young children's gross and fine motor, socio-emotional, communication and problem-solving skills, (ii) children whose parents engage with them in more home learning activities are more likely to reach developmental milestones and school readiness than children experiencing fewer learning activities at home, (iii) the more access to books and toys that children have in the home, the higher their school readiness scores, (iv) parenting education can mediate factors that have been correlated with poorer child outcomes (particularly factors of socioeconomic status and mothers' education levels), thus helping to address inequality and (v) children who are 
supported to read at home have improved literacy skills over their peers that don't engage in communitybased literacy activities. (Malik, 2018).

There is evidence that the impact of parental involvement in learning activities with their children reach beyond academic achievement and that benefits may be evident later in life as well. Studies show that children whose fathers are involved in literacy activities with them show higher social and emotional development (Allen \& Daly, 2002). They show that these children seem to be more resilient in the face of stressful events, have higher life satisfaction and social adjustment. They also seem to have greater social competence, more self-direction and self-control, more positive peer relations, more tolerance, more successful marriages, better mental health, are in more supportive relationships and display fewer delinquent behaviors (Desforges \& Abouchaar, 2003). Results from a 20-year longitudinal study of an early childhood stimulation program in Jamaica suggest that stunted children who received early psychosocial stimulation from their parents benefited from greater parental investment, improvements in cognitive and psychosocial skills, and greater educational attainment. They also achieved on average 0.6 more years of schooling than children who did not receive stimulation and were nearly three times as likely to have had some college-level education. Parents in Rwanda who participated in early childhood development program activities reported improved behaviors, including spending more time with their children, being more patient, responding to children's needs and curiosities in caring and loving ways, using homemade materials to stimulate children and help them learn, engaging their children in playing and reading activities, and involving their children in daily activities. Further, parents who participated in parenting education sessions that included messaging on positive discipline strategies and key health and nutrition messages reduced the use of negative discipline behaviors and increased positive behaviors in feeding and hygiene. (Malik, 2018)

Based on the empirical evidence that supports the vast benefits of family engagement to children's early development, interventions aimed at improving children's acquisition of foundational skills increasingly include components designed especially for parents and caregivers, many of whom may not be able to read and write themselves. For instance, in Mozambique parents initially claimed that they could not help their children. However, following participation in reading awareness workshop sessions organized by Save the Children, reading and non-reading parents alike were ultimately empowered to participate in their children's learning. (Save the Children, 2010a). In Malawi, children who had a parent attend these sessions had significantly greater vocabulary gains than those who did not have a parent attend. This workshop effect was greater for children whose parents were non-reading. (Save the Children, 2010b). In Northern Pakistan, mothers, who were traditionally not involved in children's literacy skill development, began to show more concern about their children's education following participation in reading awareness workshop sessions (Save the Children, 2011). Similarly, in the Democratic Republic of Congo (DRC), parental education program - Encadrement Parentale - targets mothers and fathers and covers education, health, and nutrition aspects of children in all provinces. In Jordan, where the psychological stress of conflict and constant movement and a lack of formal educational opportunities have negative consequences for delivery of pre-primary education services, Save the Children programs show that both home and centerbased program options can play a positive role in those settings. In Lebanon, World Vision International established Early Childhood Care and Development Programming for 0-6-year-old Syrian refugees and the most vulnerable Lebanese children that includes building of parental knowledge and skills around preprimary education, as well as identifying current helpful and harmful practices. Similarly, Sesame Workshop and International Rescue Committee (IRC) have begun to implement a project in the Middle East in consultation with local child development organizations and curriculum expert that is designed to support caregivers to rebuild and restore nurturing relationships and to provide children with the resources for coping with the impact of trauma and displacement. In Chad, the NGO iACT, began implementing Little Ripples a refugee-led program that delivers preschool in home-based settings in the community and employs refugee women to manage the in-home preschools and 
improve the social-emotional, cognitive, and physical development of refugee children. The IRC also runs a parenting program titled Families Make the Difference for caregivers of young children in Ethiopia, Burundi, Iraq, Jordan, Lebanon, Liberia, Syria and Tanzania. Evidence from the World Bank indicates that linking parenting programming to cash transfers for the lowest resourced families has positive impacts by enabling poor families to spend more on goods (food, clean water, medicine books, toys etc.) and services (health and education), allowing better time-use for families and improving families' well-being by reducing the pressure of financial strain thereby creating a household that is more conducive to children's growth and development (World Bank, 2018).

Organizations working to provide preprimary programming in FCV contexts have offered guidance on the development and implementation of such programs. For instance, following a consultation in collaboration with the Early Learning Partnership, the World Development Report (2018), highlighted that in preprimary programming approaches, considering the caregiver is essential, particularly since centerbased care can be highly inequitable and difficult to implement effectively. The report noted that the approach needs to be based on varied parenting styles and social norms, even as these may need to be adapted for better child development outcomes, learning must be enforced at home and may be supported through home-visits or parenting workshops/forums. Such workshops need to be flexible to parent's lives (for instance adjusting times to the agricultural cycle in areas where most parents are farmers). Further, the report highlighted that the media (such as television and radio) can be used to effectively disseminate messages to parents and create demand for pre-primary services and that as nutrition has a strong positive impact, school feeding must be considered in preprimary programming. The Global Partnership for Education (GPE) offers three main points of learning from their work in contexts of crisis: (i) include mother tongue and ensure local sensitivity, (ii) work with communities and hire teachers locally, and (iii) reach disadvantaged/conflict-affected areas. Similarly, UNICEF recommends the following standards be used in the development of parenting programs (UNICEF, 2016):

Standard 1: Programs should build on a theory of change that can lead to targeted results. Parenting programs should build on a theory of change that provides the pathway of change from addressing risks in target populations to achieving program objectives, through the programs dose and delivery mechanisms (UNICEF, 2016). Dosage considerations include the frequency (how often), intensity (length and depth of sessions) and duration (how long the program lasts) of the program. For instance, programs that focus on building awareness may have a lighter dosage than those aiming to change behavior, programs that intend to impact change at the child level through parents should be more intense, allow practice and follow up opportunities, and/or encourage child attendance and length of programs should consider participant schedules and resource availability. Delivery mechanisms should take into consideration alignment with the needs and characteristics of the parents and caregivers, requirement of the content and availability of financial, human and technical resources.

Standard 2: Parenting programs should try to involve all parents and key caregivers. Parenting programs should involve all parents and caregivers so that messaging about the function of parenting is cohesive and coherent within the household. Although there are not many examples of parenting programs that involve all key caregivers' certain examples that involve both the father and mother in the parenting programs have shown positive results. It is important to note that parenting support programs should not frame the father's role as just helping the mother, but rather as playing a central role in the function of parenting. An example of this is The Father's Club in Haiti which consisted of regular meetings among fathers to discuss their involvement in childcare to improve the fathers' knowledge, skills and performance in early childhood care and education.

Standard 3: Adapting to local contexts and cultures and building upon existing positive parenting practices is important. Parenting programs should adapt to the reality in which young children live, building upon and strengthening existing positive knowledge and beliefs as well as attitudes and 
practices, and increasing support to parents with new skills (UNICEF, 2016). To promote ownership and sustainability of the program, it is important to consult and involve parents and other caregivers and use local context to determine content. The program should maintain standards and appropriate content principles. For example, caregiving practices that are not conducive to positive child development such as corporal punishment, lack of communication with the youngest children, or belittling of the importance of play might be analyzed in the program curriculum as obstacles that need to be addressed (UNICEF, 2016). Negative practices can be replaced by positive and effective ways of achieving holistic child development. The inclusion of scientific rationale behind knowledge and beliefs as well as attitudes and practices might be a tool to promote sustainable nurturing care practices (UNICEF, 2016). An example of this is in Jordan, where the Better Parenting Program in Jordan, implemented by UNICEF, explicitly targeted fathers in addition to mothers. (Al Hassan and Lansford, 2011). Initially there was some difficulty with encouraging fathers to participate. UNICEF targeted this problem by starting a partnership with Imams in mosques who then explained the importance of fathers participating in childcare at mosques. This program has been brought to scale with good results, with more than 200 centers nationwide implementing the program.

Standard 4: Systemic monitoring and evaluation is required to reflect continuous success of programs. Parenting programs should enforce constant and efficient monitoring and evaluation during the program implementation cycle. This process will ensure that the program remains relevant to parents, monitor costs of implementation and highlight successes and challenges of the program. Existing Early Childhood Care and Education (ECCE) monitoring and evaluation tools, such as UNICEF's Care for Child Development (CCD) package could serve as a reference for creating and adapting a framework for a particular parenting program implementation (UNICEF, 2016). One example of a good monitoring and evaluation system is the longitudinal impact of one model psychosocial stimulation program in Turkey. The Turkey Early Enrichment Project (TEEP) was initially designed to train mothers to develop their children's cognitive abilities and improve parentchild interactions, but following years of adapting and modifying its curriculum and approaches, the program evolved to include fathers, the private sector and mass media in order to change societal beliefs, attitudes and behaviors of parents and caregivers (Kagitcibasi, Sunar, \& Bekman, 2001). 


\subsection{Lessons from eight parent education programs}

Keeping in mind that parenting models look different in various contexts with regards to the approaches to curriculum, delivery methods and training, it is useful to examine the various methods implemented across contexts to promote parent engagement in early childhood in order to derive lessons for the development of an effective program for South Sudan. Bearing in mind the context of South Sudan, five key criteria that guided selection of the programs included: (i) low cost of implementation, (ii) use of local resources, (iii) creation of contextually relevant curriculum, (iv) supporting parents who do not know how to read/write and (v) evidence of benefits following empirical testing.

\section{Lively Minds (Ghana)}

Program Description. In 2007, faced with low levels of maternal education and in order to address a lack of trained teachers, large class sizes, lack of play-based resources, teacher absenteeism, and an emphasis on rote-based teaching in rural preprimary classrooms in Ghana (Amadu, Attanasio, Caeyers, Cattan, Sosa, Krutikova, \& Yakubu, 2018) the Ghana Education Service (GES) joined Lively Minds, a local NGO, to boost parent engagement in home and preprimary school environments.

The training model began by sensitizing district-level staff around early childhood development and supporting them to deliver program activities to kindergarten teachers. Two teachers from each school were then trained by Lively Minds staff and district officials for five and a half days on the importance of play, management of play schemes, how to create and play learning games, and how to train mothers to facilitate play schemes. The teachers, in turn, trained 30-40 mothers on the importance of education and play, how to make and play games, how to facilitate Play Schemes, child-friendly teaching and how to install simple handwashing devices (called tippy taps). This training was scripted and targeted towards mothers who may be unable to read. For four days per week/one hour each day, groups of trained mothers came to preprimary classrooms during school hours to facilitate the play schemes or outdoor play. Each Scheme was provided with a starter pack of games (including bottle top counters, cardboard puzzles, dominoes, sorting games, wooden blocks/shape sorters), and mothers were trained to make their own games.

During the Play Schemes, children were divided into small groups and moved around the following five play stations: matching/sorting; numeracy; sizes, colors, and senses; books; and building. Mothers facilitating the play stations taught 5-6 children at a time using participatory, child-led, turn-taking methods, rather than the rote-methods which are usually found in formal classroom settings in Ghana. Mothers facilitating outdoor play focused on strengthening children's physical development, social skills, ability to follow instructions and cultivate an interest in local culture. Volunteer mothers and children washed their hands using the locally produced tippy taps at the beginning of each session. Since the scheme took place in pre-primary classrooms, no construction costs were required. Each month, teachers followed up with mothers in workshops and covered topics including parenting (communication, playing at home, makebelieve), health care (nutrition, malaria prevention, home hygiene) and life skills (wellbeing, financial management, time management). These monthly workshops incentivized mothers to continue volunteering in the program and benefitted both the children in the Play Schemes as well as the mothers' own children at home. District staff and Lively Minds staff conducted regular monitoring visits to ensure implementation quality. District staff also conducted follow up training workshops for teachers. 
Figure 1: Lively Minds Parent Engagement Model

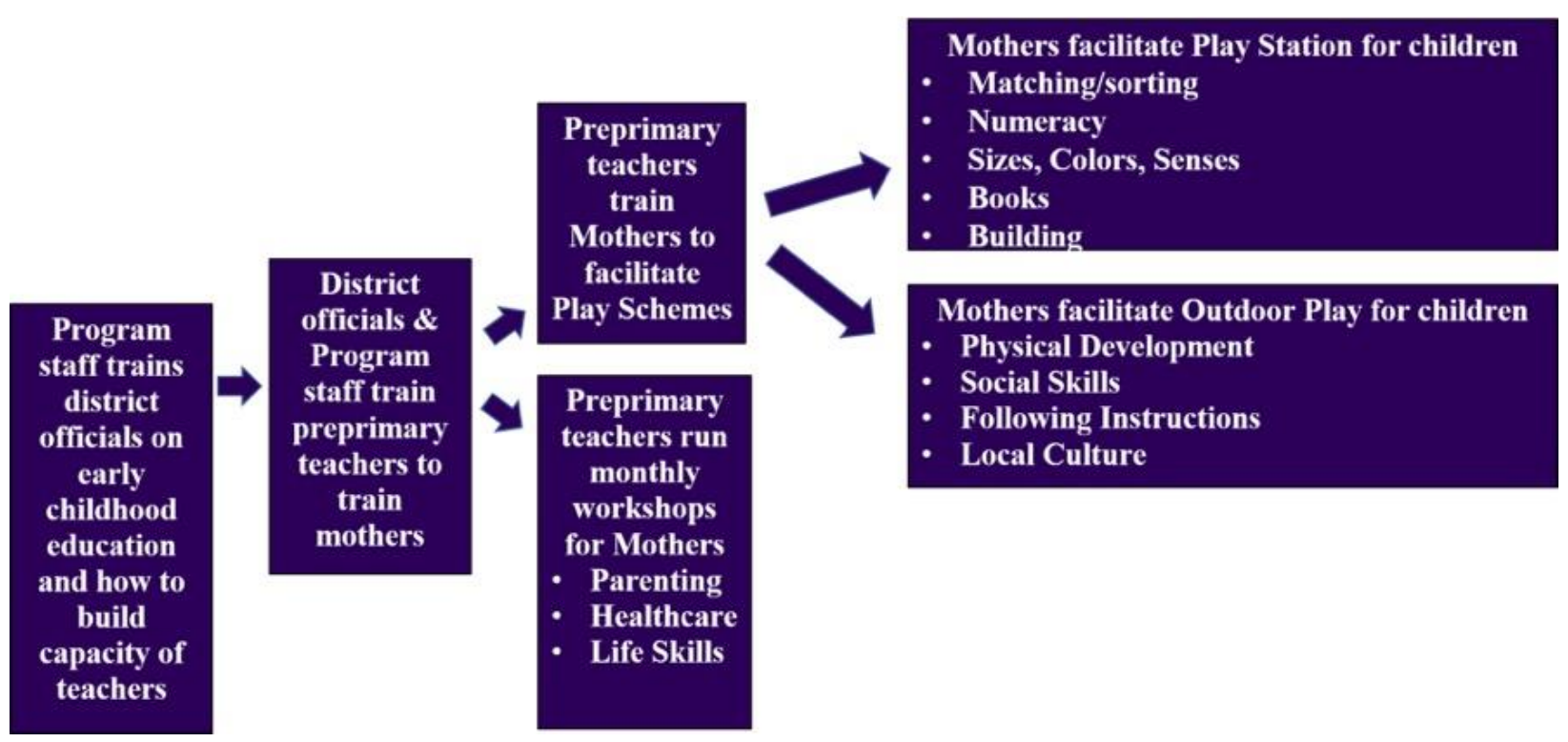

Program Impact. A randomized trial conducted by the Institute of Fiscal Studies found that overall the Lively Minds program improved children's cognitive and socio-emotional development and reduced child acute malnutrition. The program improved children's overall cognition score by 0.14 standard deviations, driven largely by substantial improvements in emergent numeracy, executive functioning and fine-motor skills. These children also experienced significant improvements in literacy (Amadu et al., 2018). Although cognitive skills improved for all children, benefits were greatest for children from the most socio-economically disadvantaged homes. There was a 53\% increase in school readiness assessment results after 6 months of the program as well as a 53\% increase in reported play at home. There was also a reported $62 \%$ reduction in diarrhea and $46 \%$ reduction in malaria among participants six months after the program. The program reported a $2 \%$ absenteeism of teachers affiliated with the program as compared to $25 \%$ average teacher absenteeism in the country. Overall, the program was cost-effective (Dhaliwal, Duflo, Glennerster, \& Tulloch, 2013) in increasing cognitive skills, leading to 1.7-2.5 additional years of schooling per US\$100 spent (Evans \&Yuan, 2018).

\section{Key Considerations from the Lively Minds Program}

- Engagement of local education officials fosters local ownership of the program

- Ongoing support for facilitators ensures sustainability and quality assurance of the program

- Including topics of interest to parents in workshop content supports volunteer engagement

- The lowest resourced families and children may benefit the most from programming 


\section{Little Ripples (Chad and Cameroon)}

Program Description. Set up by the NGO iACT, Little Ripples ${ }^{2}$ is an early childhood development program that empowers refugee communities to implement pre-primary education to support the socialemotional, cognitive, and physical development of young children ages 3 to 5 years impacted by trauma, violence and displacement (Dallain \& Scott, 2017). iACT staff and ECD experts engage with refugees and community members to learn about the program approach and adapt the activities to their specific context. The curriculum is based on play-based education, trauma-recovery approaches, restorative practices, and incorporates social-emotional learning, empathy development, positive behavior management, peacebuilding, and mindfulness (Bouchane, Yoshikawa, Murphy, \& Lombardi, 2019).

Women refugees receive three trainings over the course of a year and ultimately take over all program activities (which may happen in any location that is suitable and accessible to participants). Training includes an overview of the Little Ripples pillars (peace, helping, sharing), teacher responsibilities (ensuring children feel safe, at peace and have fun), play based learning (directed play, free play and outdoor play), positive behavior management, emotional literacy (understanding and expressing emotional feelings), storytelling (the impact of hearing and seeing stories on children), health and hygiene (use of latrines and handwashing practices), mindfulness (breathing exercises, walking and movement based mindfulness), creating daily schedules, monitoring and program management, and weekly meetings (important for discussing solutions). Following training, each participant receives a Lead with Empathy leadership with human rights curriculum to complete during weekly meeting.

The outline of the curriculum allows teachers (women/parents from the community) to adapt the curriculum with activities, songs, stories, and games unique to their culture. Teachers identify moments throughout the school day to talk about the pillars with students. The mindfulness component of the program is designed to support refugee children (as well as their teachers) to find peace from the instability of camp life (Bouchane et al., 2019). Students learn to be resilient, manage their emotions, build positive relationships, concentrate, and play cooperatively with others. Little Ripples students learn literacy and numeracy through structured play, free play, and outdoor games. To encourage peacebuilding and empathy, teachers lead age appropriate mindfulness exercises as well as employ nonviolent communication and positive behavior management techniques (Bouchane et al., 2019).

Figure 2. Little Ripples Parent Engagement Model

2https://static1.squarespace.com/static/583af1fb414fb5b3977b6f89/t/59bdb9c703596e9e8b02d5b8/1505606090047/6 Promi singPractices iACT WEB.pdf 


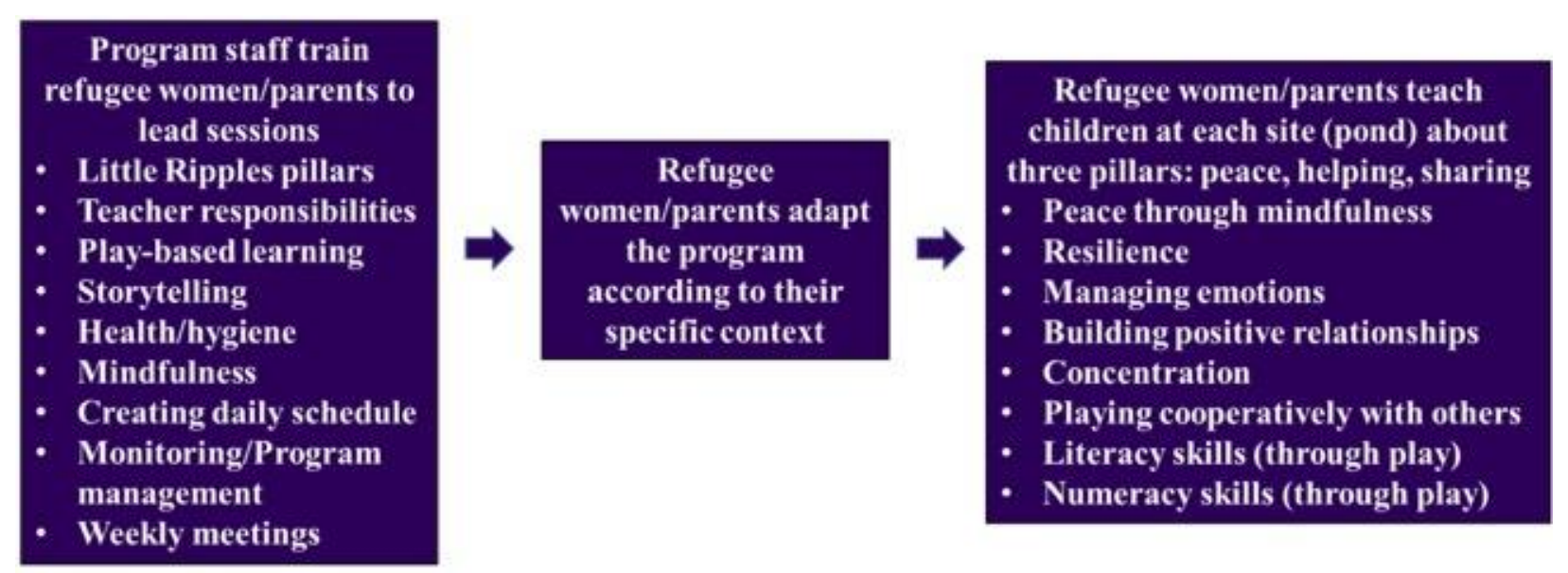

\section{Program Impact.}

Participation in the program has been found to be associated with gains in numeracy and literacy skills of young children. A baseline and a one year follow up of the program conducted with 134 Little Ripples students and their caregivers showed that following participation in the program (i) The number of students able to name colors increased from $27 \%$ to $51 \%$, (ii) the number of students able to count to five or higher increased from $43 \%$ to $73 \%$, (iii) the number of students able to identify four or more animals from pictures increased from $21 \%$ to $63 \%$ and (iv) the number of students able to recite at least the first ten letters of the alphabet with no mistakes increased from $45 \%$ to $83 \%$.

Since collecting and receiving regular data regarding attendance and observations of various socioemotional behaviors of students was an initial challenge, iACT created a tool that aided this process for mothers/teachers. iACT chose to focus on impact rather than number of children reached. The demand for the program was high but the program started small and limited attendance (three sites (ponds), six teachers, and 135 children (45 per pond). To address this, communitywide Little Ripples celebrations are held to better inform others of the program structure, expected impact, and long-term plans, and program staff conduct outreach to discuss the program's approach and communicate long-term plans to reach all children (Bouchane et al., 2019).

\section{Key Considerations from the Little Ripples Program}

- Allowing parents/community members leadership/management of the program

- Adapting the program according to the availability of space

- Focusing on quality of programming rather than number of children reached may allow a program to start small and refine prior to scaling up. 


\section{Emergent Literacy and Math Initiative (Rwanda)}

Program Description. The Rwandan Emergent Literacy and Math Initiative (ELMI), managed by Save the Children, aimed at more inclusive and effective learning for all pre-school children to better prepare them for entering primary school. The ELMI program has to date, been implemented in 20 different countries (Amente et al., 2017). In Rwanda, the approach has been embedded in the government curriculum for pre-primary education (Amente, Yenew, Borisova, Dowd, Pisani, Dang, \& Anís, 2017). The model cost about $\$ 10$ per child per program cycle, in Rwanda.

The project had two separate components in Rwanda:

- A first component aimed to improve the quality of teaching of literacy and mathematics skills in ECD centers. This included supporting caregivers to create a stimulating, age-appropriate and engaging learning environment (Amente et al., 2017).

- The second component worked with parents of children not able to access formal ECD services and trained them on simple activities they could do at home to support their children's learning.

The second component, a parent outreach initiative in areas where there were no ECD centers was added to the delivery model in Rwanda with the aim of maximizing the impact of the initiative for all children (CEI, n.d.). This training of parents (many of whom had not attended school themselves) to support the school readiness of their children through simple, practical learning activities in and around the house was a new way of working in Rwanda (CEI, n.d.).

In this component, parents of children aged 4-6 years participated in nine weekly sessions where they learned how to make and play literacy and numeracy toys and games with their pre-primary aged children. Session facilitators included previously trained parents or preschool class facilitators. Parents were more readily engaged by being trained to do simple activities with their children that can be conducted in and around the house, in the market, etc. Literacy activities includied in the ELMI curriuclum are related to Talking and Listening, Understading letters, Knowing what books are and Understanding sounds and words. Numeracy activities include Numbers and counting, Patterns, Sorting and Classification, Comparison and Measurement and Geometry/Spatial relations. Activites introduced during ELMI encouraged parents and other caregivers to engage their children. For example: learning counting skills by counting objects when doing small purchases, learning sorting skills during food preparation and reading together or talking about pictures in a book. The activity cards provided helped parents easily remember the 'lessons' and what to do (CEI, n.d.).

Each session was thematic and covered up to three games that parents could play with their children. Following these sessions, parents participated in playgroups where they were able to practice playing the games with their young children. 
Figure 3. Early Literacy and Math Initiative Parent Engagement Model

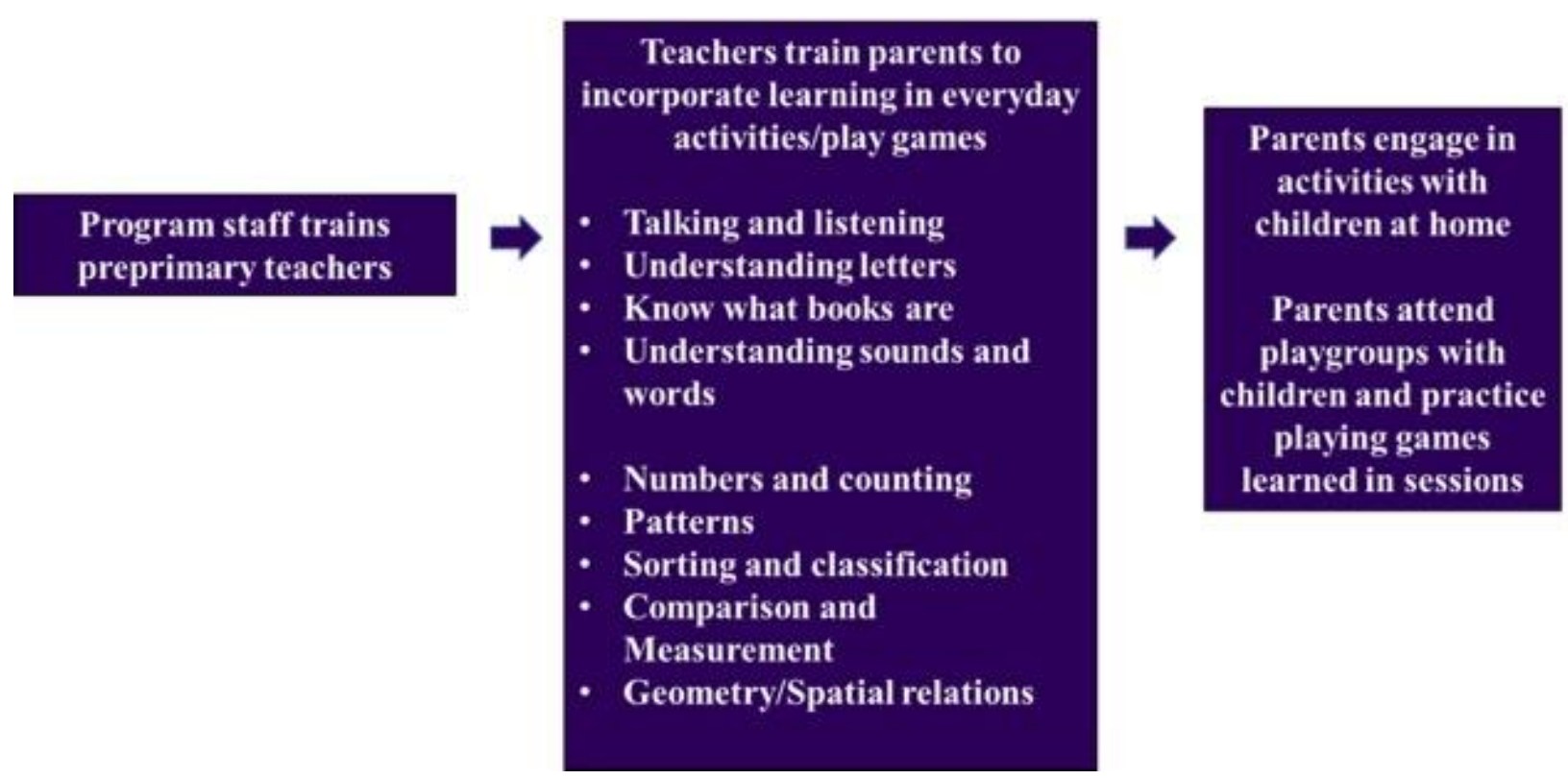

Program Impact. The program was evaluated using a longitudinal study conducted by Save the Children in June 2015, where the baseline data was collected in May 2013. The findings demonstrated that (i) children in the ELMI Centre and ELMI Parenting groups showed significantly higher scores at endline on both literacy and math compared to children in the Non-Early Childhood Care and Development (ECCD) control group, (ii) ELMI parenting children started off lowest across all groups on all areas at baseline and over time caught up almost entirely with their ELMI ECCD peers, closing the gap from baseline and (iii) not only do the ELMI Centre and Parenting programs produce strong learning gains on average, but these interventions are helping all families and children equally, irrespective of socioeconomic status (Save the Children, 2015).

Another study indicated that the ELMI parenting component in particular showed interesting elements of parent empowerment; parents started to understand that they had something to offer to their children in terms of learning, even if they may not have attended school themselves (CEI, n.d.).

\section{Key Considerations from the Early Literacy and Math Initiative Program}

- Parents can be supported to learn about simple, practical learning activities in and around the house to engage in with their child

- Parents may be taught simple games that they can play with their children to support literacy and numeracy skill development

- Additional time and space to practice skills and games learned in parenting sessions may be provided to parent-child dyads in the community 


\section{Mother Child Education Program (Turkey)}

Program Description. The Mother Child Education Program (MOCEP) began in Turkey in 1993 and aimed to support preschool aged children who had been exposed to risk factors, such as poverty, political and armed tension and parents with low education levels. The core of MOCEP's work was the acknowledgement of the importance of parents and caregivers' roles in the development of young children and training them as a child's "first educator". MOCEP, the flagship program of the Mother Child Education Foundation (ACEV), is a 25-week long, low-cost, home-based program for mothers whose children do not have access to pre-school education services. The program targets both mother and child in a two-step process.

Each week, a group of up to 25 mothers meet for 2- 3 hours during which they are provided with the knowledge and skills necessary for child development and training. The classes are taught in discussion format where an ACEV trained group leader facilitates the learning (ACEV, 2019). The trainers then begin conducting the courses with a mother group over a period of 25 weeks. In addition to the weekly group sessions, trainers also conduct individual home visits (ACEV, 2019). Trainers are also responsible for recruitment of mothers in their communities, liaising with local NGO's and authorities. ACEV master trainers and experts continue to provide trainers with effective and systematic in-the-field support and supervision to maintain quality and consistency (ACEV, 2019).

Each mother receives a 10-20-page booklet each week for the duration of the 25 weeks, containing exercises that the mother conducts at home with the child. These exercises support the cognitive and fine motor skills of the child (ACEV, 2019). The program targets both the mother and the child with educational outcomes aimed at both groups. It enriches children cognitively in order to boost school readiness and optimal pyschosocial development, and trains mothers, creating sustainable nurturing and healthy home environments (ACEV, 2019). Although the target group is the mother and her young child, indirect beneficiaries include other siblings and spouses who benefit from the enriched home environment and positive communication skills of the mother (ACEV, 2019).

Figure 4. Mother Child Education Program Parent Engagement Model

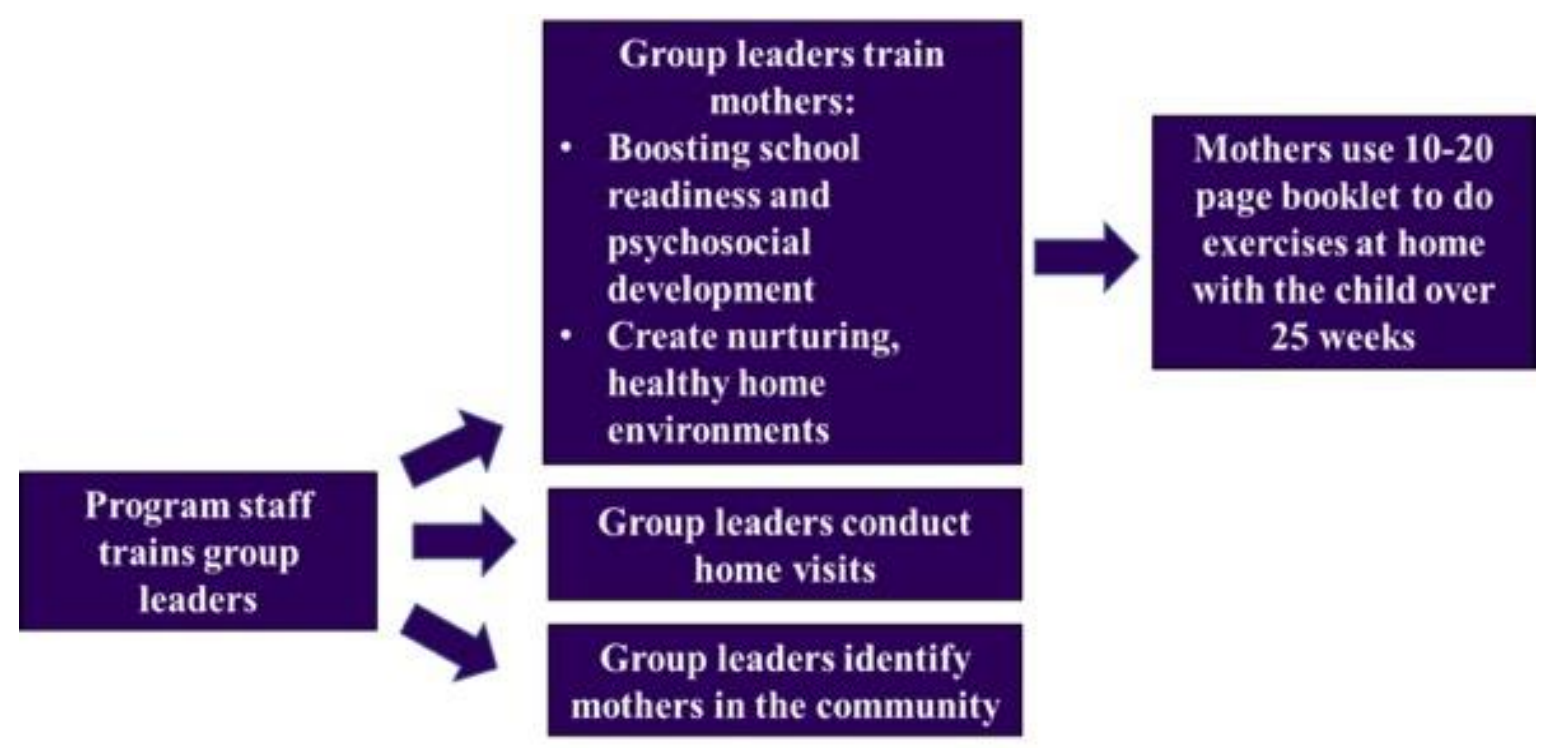


Program Impact. Studies have found that with MOCEP children are better equipped for school, show lower drop-out rates and consequent success in education resulting in better life choices and results than their peers. Empowering mothers guaranteed that the environment of the child is permanently changed with the likelihood to promote self-sustaining changes and growth. Impact has also been proven on mothers as they report better relations with children and spouses as a result of positive parenting, self-esteem and improved communication skills.

At the macro policy level significant impact has also been demonstrated; since 1993 the program has been implemented in partnership with the MoNE in order to maximize on available resources (staff and Adult Education Centers). This partnership has today been established, where the importance of Early Childhood Education (ECE), consisting of both formal center-based preschools and home-based early improvement models, have been recognized as a policy priority by the Turkish government, impacting the lives of millions of Turkish children.

\section{Key Considerations from the Mother Child Education Program}

- 25 week long, low cost home based program for mothers

- Master trainers train trainers who train mothers for 25 weeks

- Mothers use 10-20 page booklet each week for activities to do with child

- Cognitive and fine motor skills

- Strong process monitoring 


\section{Parents Make the Difference (Liberia)}

Program Description. The Parents Make the Difference program consisted of 10 weekly group sessions and an individual home visit to each family (Giusto, Friis, Sim, Chase, Zayzay, Green, E. \& Puffer, 2017). Each two-hour weekly group session was facilitated by two Liberian staff from the International Rescue Committee (IRC), who were trained on and had experience with the content and delivery of the program. Group sessions were created to be highly interactive, with a strong emphasis on modeling, discussion and in-session practice of skills. The program was unique in its adaptation of evidence-based parenting strategies for a low resource, post conflict setting, as well as for its multi-sector approach, including sessions on positive parenting, cognitive development, and malaria prevention (Giusto et al., 2017).

Session topics included: negative effects of physical and psychological punishment and alternatives to harsh punishment; positive parenting skills; how to promote children's numeracy, vocabulary, and communication skills; and malaria causes, symptoms, prevention, and treatment. Facilitators conducted a home visit to provide individualized support, and participants formed support groups to review program content. Intervention fidelity (i.e., facilitators' adherence to program delivery and curriculum) was monitored by IRC technical and program staff. Participants also created Parent Support Groups (PSG's) to increase group discussions and share learnings with each other (Giusto et al., 2017).

Figure 5. Parents Make the Difference Parent Engagement Model
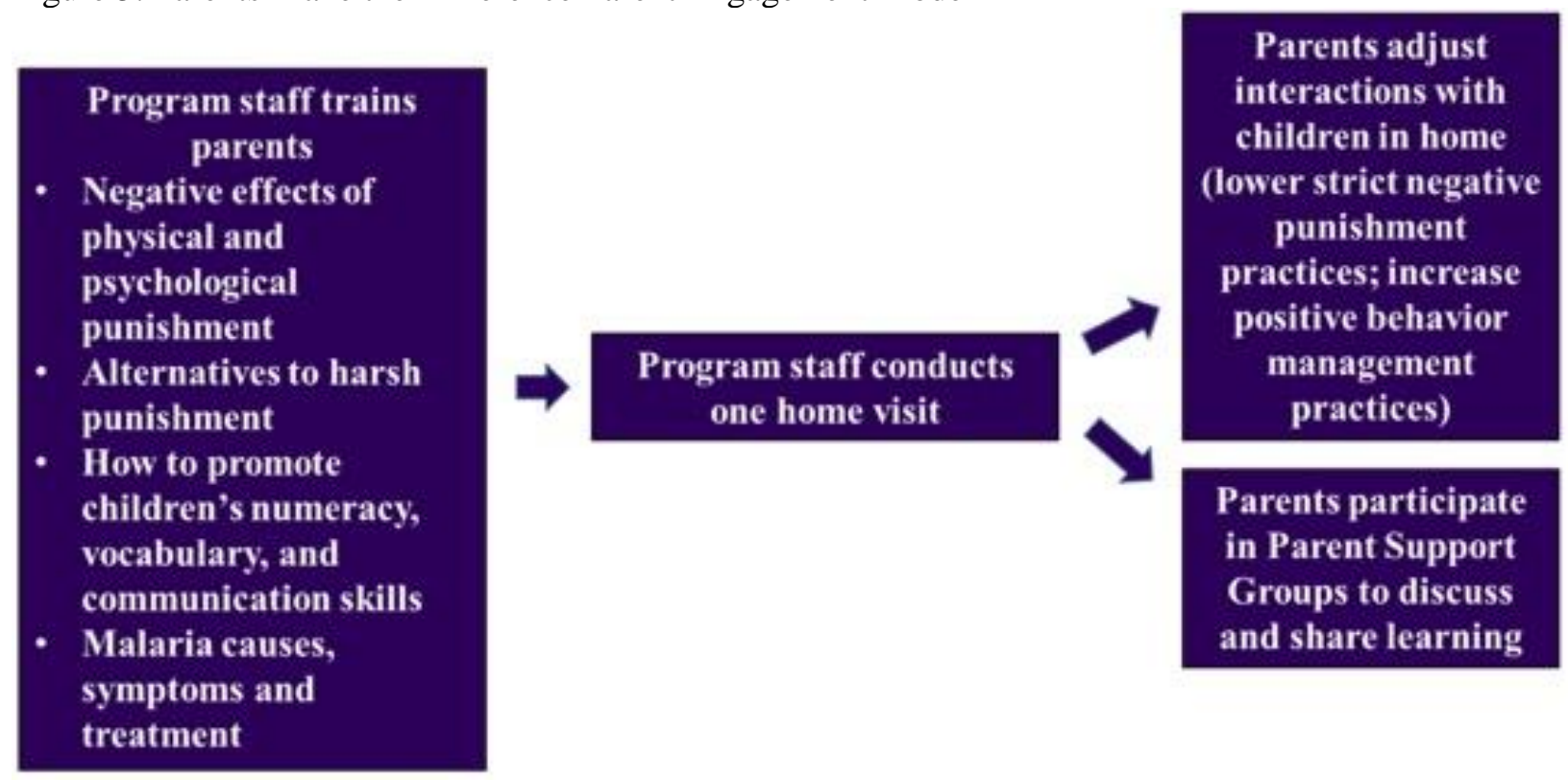

Program Impact. The impact evaluation used a randomized waitlist-controlled trial design to examine the impact of the intervention on: 1) caregivers' parenting practices; 2) children's cognitive, social, and emotional outcomes; and 3) malaria prevention behavior (Sim, 2014). Evaluation found that the intervention was reasonable and acceptable in this low-resource, post conflict setting, significantly lowered the use of strict physical and psychological punishment and significantly increased caregivers' use of positive behavior management practices and enhanced the quality of caregiver-child relationships. However, the intervention did not have a noteworthy impact on children's cognitive, emotional, or behavioral outcomes. 


\section{Key Considerations from the Mother Child Education Program}

- Parent Support Groups provide a space for parents to discuss and share learning outside of the workshops

- Parenting workshop may target a specific health concern (commonly affecting children in the context)

- Impact may stop at altering parent behavior and not show impact on children (or not within the given timeframe) 


\section{Literacy Boost Community Action (Rwanda)}

Program Description. Implemented by Save the Children, the Literacy Boost Program is a program that emphasizes the importance of parental engagement in promoting children's literacy skills. One of the main components of Literacy Boost is Community Action which aims to provide support to parents and communities to support children as they learn to read. The other two focus areas of the program are Reading Assessments and Teacher Training. Community Action contains specific activities that allow for reading to happen outside of a formal classroom by focusing on a varied number of texts and reading activities that involve the family. Literacy Boost emphasizes that everyday activities have the potential to boost children's learning of letters, sounds and words, and contribute to the development of their knowledge of the world around them. The Community Action component includes seven session guides for conducting reading awareness sessions with parents. An accompanying flipbook, Community Strategies to Promote Literacy, supplements parent sessions. (Save the Children, 2012)

In the Reading Awareness Workshop sessions, parents learn how to support the early literacy development of their children by reading with and to their child at home and using locally available material. In addition to the workshops, communities engaged in the Literacy Boost project benefited from other community level activities such as reading clubs, book banks, book buddies and reading festivals. In Rwanda, parent/youth volunteers were enlisted and trained to lead sessions, ensuring ownership and sustainability of projects at the village level. Rather than targeting the children, RAWs are geared towards supporting parents, family members and other caregivers to bolster early literacy development.

In Rwanda, each session lasted for about 1.5 hours, occurred in a location convenient for family members and was led by program staff members and/or trained local volunteers (in some cases youth from within the communities). Sessions focused on reading with children and creating a rich print environment using locally available resources. Participants were also instructed on ways to support the oral language development of children, indicating the important role that parents could play regardless of their own level of literacy skill. Topics included (i) Brain Development, (ii) Emotional Wellbeing/ Social Competence/ Positive Images, (iii) Cultural and Spiritual Roots, (iv) Children's Language and Literacy Development, (Everyday Activities for Reading Readiness, (v) Reading to/Telling Stories to Children, (vi) Reading to Children Feedback and Reading with Children, (vii) Creating Reading Materials to Help Children Learn to Read, (viii) Reading Corners

After a few sessions, once parents were more familiar with the program, a pair of parents from within each village was selected to be trained and later to conduct reading clubs for children in the community. 
Figure 6. Literacy Boost parent engagement model

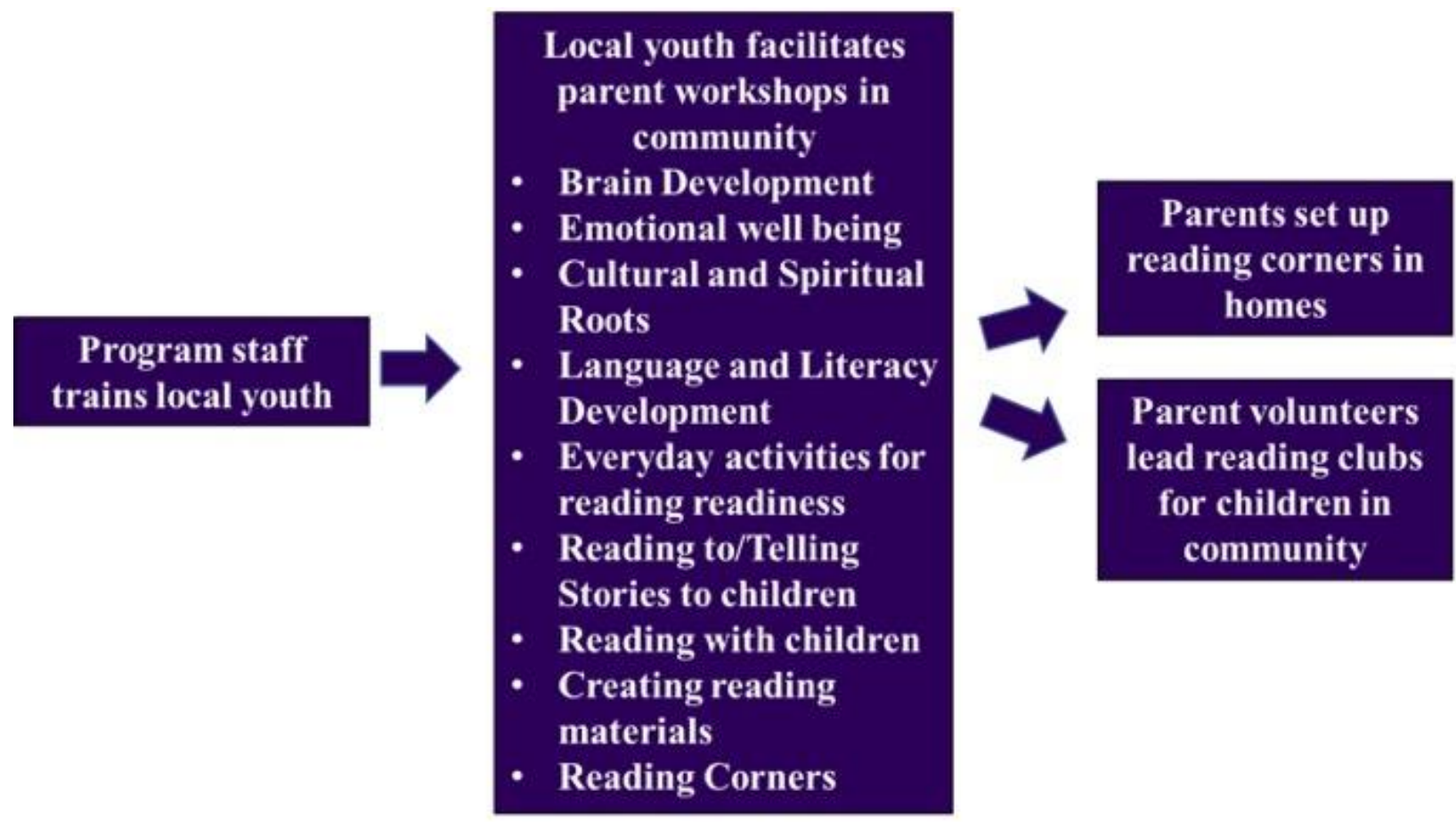

Program Impact. Save the Children collaborated with Stanford University to conduct a randomized control trial (RCT) to study the impact of Literacy Boost and specifically to explore added benefits of engaging families and communities in literacy skill development above and beyond teacher training in early grade reading instruction. The RCT found that involving families and communities created a greater number of readers who read fluently and with comprehension than simply training teachers alone (Friedlander \& Goldenberg, 2016). Overall, combining teacher training with community action, had a larger observable impact than teacher training alone. Moreover, two years of treatment had a higher impact than one year alone (Friedlander \& Goldenberg, 2016).

\section{Key Considerations from the Literacy Boost Program}

- Parent sessions timing and location should consider parent schedules

- Locally available material may be resourced to make simple teaching and learning materials for the home

- Parents may be supported to create learning spaces for children in their homes

- Parent workshops may be supplemented with child-focused sessions in communities

- Local youth may be incentivized to facilitate parent sessions

- A combination of direct instruction, modeling, hands on practice and role-play keeps participants engaged

- Some program impact may take time to be observable 


\section{First Steps (Rwanda)}

Program Description. Designed by Save the Children, First Steps aimed to achieve improvements in parenting practices, child development indicators, and increase emergent literacy promotion for children 03 years of age in the home. The parenting sessions were delivered in the community by trained local volunteers supported by a radio program. This approach ensured that the program was able to reach a greater number of children and parents for less cost. Sessions were conducted weekly over a period of 17 weeks and each session lasted approximately 75-90 minutes. Families also received an average of two home visits during the intervention and vulnerable children or families received additional home visits. The program content focused on 4 key areas: responsive caring, playful learning, language and literacy, and health beginnings. The package included a facilitators' guide, illustrated take-home activity cards on parenting practices, one children's book per family, and a demonstration of home book-making using local supplies. Children attended sessions with their parents each week, so sessions included time for parents and children to practice activities that were taught. At the end of each session, parents checked out books to read with their children at home. At the end of the program, parents were gifted books to keep. The program focused on encouraging men to participate in parenting activities and allowed the volunteers to practice parenting facilitation exercises with parents at home.

Figure 7. First Steps parent engagement model

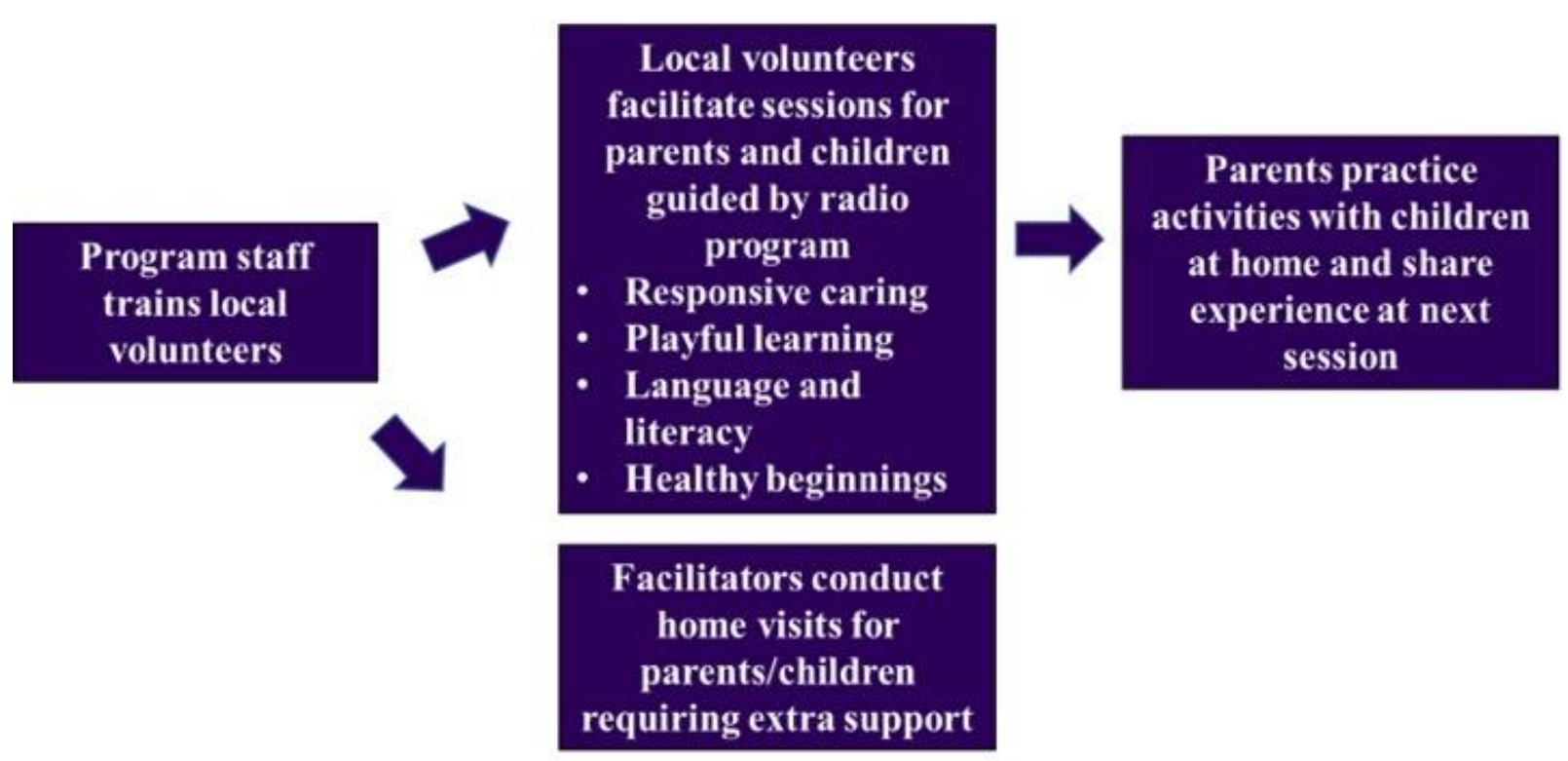

Program Impact. A randomized controlled tria1 of the pilot phase of First Steps in Rwanda found: (i) improved child health and nutrition practices, (ii) improved parent-child engagement and (iii) increase in children reaching appropriate developmental milestones following programming.

Significant gains in nutrition and health practices were observed within First Steps intervention group parents. Parents reported breastfeeding more frequently, giving children solid food more frequently more handwashing and with soap at endline than at baseline. First Steps improved caregivers' parenting attitudes and practices with their children. Over time, caregiver perception of parental importance in children development increased significantly in the intervention groups compared to the control group. Also, both mothers and fathers reported engaging in significantly more learning/play and nurturing/care behaviors, 
engaging in fewer negative discipline behaviors, engaging in significantly more learning/play activities. Taken together, this indicates that both the light touch and full intervention programs had a significant positive impact on mother-child and father-child interactions.

Attending more parenting sessions was positively related to parent attitudes toward child development, mother-child learning/play activities and maternal use of nurturing/care behaviors at endline. Mothers of all education levels and those who have many children at home were able to benefit from parenting session however, poorer mothers may not have benefitted as much as wealthier mothers. Parents who reported listening to more radio programs also reported less negative discipline behavior (e.g., yelling, hitting, spanking) with children. The First Steps program improved children's early learning and development. At endline, children in the treatment group were significantly more likely to meet the ASQ benchmarks than children in the control group in all areas except gross motor development where the difference was only marginally significant for the full intervention group $(\mathrm{p}<.1)$. Finally, higher attendance at parenting sessions was significantly positively related to meeting the communication benchmark, and more radio listening was significantly positively related to meeting the communication and gross motor benchmarks which again highlight the positive impact of various components of the First Steps program on children's development. (Pisani, Abimpaye, Nzabonimpa and Dusabe, 2016).

\section{Key Considerations from the First Steps Program}

- Radio broadcast to facilitate in person discussions can help to increase reach and ensure uniformity across groups in different locations; may be an important consideration when social distancing measures are required

- Parent workshops can offer a potential space for book borrowing

- Home visits can supplement parent sessions, particularly for families with greater need

- Take home cards/leaflets may help parents to practice activities discussed in sessions at their homes

- Children attending sessions with parents allows for practice of activities discussed 


\section{Reach Up and Learn (Lebanon, Jordan, Syria)}

Program Description. Funded through a grant from the MacArthur Foundation, the IRC and Sesame workshop began implementation of a program named Ahlan Simsim in the Middle East to support parents and other caregivers. The program aims to create access to a localized version of the Sesame Street (educational entertainment for children) programs through mobile phones, television and other digital platforms. The program aims to support 9 million children to build skills in literacy, numeracy and socioemotional development.

One component of the program provides home visit support to parents and caregivers. Based on the Jamaica home visiting program (Grantham-Mcgregor and Walker, 2015), the home visit approach, called Reach Up and Learn, ${ }^{3}$ consist of a 10-day course to train community members to become home visitors, and support caregivers in providing a stimulating environment for children that facilitates interaction and learning. Home visitors meet with parents in their homes weekly or biweekly to discuss and model positive, playful and stimulating interactions using age-appropriate activities with children. The goal is for parents to become confident in their ability to have similar interactions and engage in learning activities with their children. Home visitors prepare weekly activities, including making simple toys from locally available material such a plastic bottle, bottle tops, cardboard and other found objects. These toys are used for multiple activities and sessions. Some of the books and other materials used relates to the Ahlan SimSim program. Home visitors leave behind the toys or books used during the session so that parents and caregivers can continue to practice activities with the child, while taking the materials used the previous week and rotating them among families. During the session, the home visitor models an activity with the child, then allows the parent and child to practice the activity, providing praise to both as they do so. The modeling approach encourages the caregiver to have a strong, healthy relationship with their child to enhance caregiving and childrearing practices in a way that is beneficial for the whole family. ${ }^{4}$

Figure 8. Reach Up and Learn parent engagement model

\begin{tabular}{c|c|c|c|}
$\begin{array}{c}\text { Program staff } \\
\text { trains }\end{array}$ & $\begin{array}{c}\text { Home visitors visit homes } \\
\text { weekly or biweekly modeling } \\
\text { activities and interactions for } \\
\text { parents-share home made toys } \\
\text { members as } \\
\text { home visitors }\end{array}$
\end{tabular}$\Rightarrow$\begin{tabular}{c}
$\begin{array}{c}\text { Parents learn skills and gain } \\
\text { confidence to have healthy, } \\
\text { stimulating interactions with } \\
\text { children-practice home made } \\
\text { with toys and books }\end{array}$ \\
\hline
\end{tabular}

Program Impact. While a randomized controlled trial is being planned for this program, initial qualitative study shows that the program alleviated caregiver stress and allowed for collaborative learning, opening up opportunities for children to interact more with their caregivers. There is also evidence that children are learning to differentiate shapes, animals and colors as well as engage more generally with activities through this program.

\footnotetext{
3 http://www.reachupandlearn.com/

4 https://www.rescue.org/sites/default/files/document/4803/irc-rul-reportapril27-2020.pdf
} 


\section{Key Considerations from the Reach Up and Learn Program}

- In addition to providing skills to parents, it is important to build parent self-efficacy to have positive and healthy interactions with their young children

- Modeling activities for parents, in their homes, and providing praise to both parent and child as they engage in the activity helps to build a comfortable 'whole family' approach

- Home visits can complement other activities (such as edutainment) to provide direct guidance and support to parents and caregivers and encourage practice of learning activities in the home 


\subsubsection{Key challenges faced by parenting programs}

Although the programs reviewed had varying degrees of success, there were a number of documented challenges faced by each. It would be wise to anticipate similar challenges and build mitigating features into the design of any parenting program being developed for South Sudan:

Parent/caregiver recruitment: One challenge that was mentioned in analysis of the Little Ripples program was the management of participant recruitment in the program because of the high and increased demand for preschool services. Given that there are few to no alternative preprimary programs in low resourced contexts, the demand for such programming may be high and more than the capacity the program allows. In this case, it may be useful to create communication material that clearly explains resource limitations as well as the importance of maintaining a small number of participants per group and learning from a smallscale version of the program before expanding to a larger scale of high quality. In some cases, a cascade model of information sharing may be considered, whereby parents who participate in the program directly may share information with other caregivers in the community.

Managing participant expectations: A related challenge is the expectation of parents that a program may provide resources including cash transfers, nutrition and health services or materials such as toys and books for children. It is important to be clear about what the program will and will not be able to manage at the onset of engagement with parents so that expectations are managed early on. In some cases, where feasible, parents and families may be referred to other partners or organizations that may fulfill service requests.

Buy-in from government and resource consistency: Another key challenge may be sustaining governmental buy-in to the programs given frequent turnover in ministerial leadership and personnel. It is also challenging to maintain implementation quality and local staff sustainability as well as continuous funding. This may be mitigated through consistent communication with government counterparts where positive results are highlighted so as to work towards continuous buy-in.

Consistency of caregivers: Some programs experience changes in the parent or caregiver who attends sessions or is present during home visits. This may cause a dip in consistent knowledge sharing. It may be useful to communicate with families early on that the same person, preferably the primary caregiver should attend all sessions or be present at all home visits to ensure sustainable knowledge sharing and for greatest positive impact.

Retaining a motivated workforce. Another common problem experienced by some programs is high staff turnover, meaning that the people initially trained facilitate sessions or conduct home visits do not continue with the program. Programs must explore effective incentives (preferably non-monetary to ensure sustainability and local ownership) for facilitators so retain them in the long run.

Going to scale: Scaling-up of parenting interventions is limited by the technical capacity of organizations to implement them. In some cases, empirical evidence of program impact creates buy in and funding opportunities (federal and external) to scale programs up nationally. In those cases, the challenge created is to maintain positive benefits when implementing at a larger scale. This requires consistent support and supervision as well as consistent access to necessary materials, training and technical support. The most serious challenge in going to scale has been that funding pressures often push organizers to reduce the inputs to an extent that limits the intervention's effectiveness. This is a complex balance that needs to be considered in the design of any parenting program. 
Addressing both child and adult focused outcomes: This challenge is not restricted to just one of the eight programs analyzed in this desk review. Parenting programs are designed in a way that keeps the children at the center, but it is equally important to address any challenges that parents or caretakers might face that could impact the activities and outputs of the workshop. In the case of South Sudan, like in many FCV contexts, a challenge that could arise is if the project did not take into considerations various challenges and traumas that parents and caretakers face including literacy levels, stress and psychosocial trauma and the impact of COVID-19 on the community. To address this challenge, the World Bank team has developed a phone survey that can be conducted to gather data on how parents are coping with additional demands and the resources that are already available to the family. 
Table 1. Summary of parenting programs reviewed

\begin{tabular}{|c|c|c|c|c|c|c|c|}
\hline Name & $\begin{array}{l}\text { Delivery } \\
\text { Modality }\end{array}$ & $\begin{array}{c}\text { Taskforce/ } \\
\text { Facilitators }\end{array}$ & Beneficiaries & $\begin{array}{l}\text { Frequency/ } \\
\text { Duration }\end{array}$ & Content & Results & Considerations for South Sudan \\
\hline Lively Minds & Workshop & $\begin{array}{l}\text { Kindergarten } \\
\text { teachers }\end{array}$ & $\begin{array}{l}\text { Mothers (20- } \\
30)\end{array}$ & $\begin{array}{l}\text { Two 2-hour } \\
\text { community } \\
\text { meetings and } \\
\text { eight 2-hour } \\
\text { participatory } \\
\text { workshops }\end{array}$ & $\begin{array}{l}\text { The importance of } \\
\text { education and play, } \\
\text { how to make and play } \\
\text { games, child-friendly } \\
\text { teaching, and how to } \\
\text { install simple } \\
\text { handwashing devices } \\
\text { (tippy-taps) at home. }\end{array}$ & $\begin{array}{l}\text { - improved children's cognitive and socio-emotional } \\
\text { development and reduced child acute malnutrition. } \\
\text { The program improved children's overall cognition } \\
\text { score by } 0.14 \text { standard deviations, driven largely by } \\
\text { substantial improvements in emergent numeracy, } \\
\text { executive functioning and fine-motor skills. These } \\
\text { children also experienced significant improvements } \\
\text { in literacy (Amadu et al., 2018). Although cognitive } \\
\text { skills improved for all children, benefits were } \\
\text { greatest for children from the most socio- } \\
\text { economically disadvantaged homes. There was a } \\
53 \% \text { increase in school readiness assessment results } \\
\text { after } 6 \text { months of the program as well as a } 53 \% \\
\text { increase in reported play at home. There was also a } \\
\text { reported } 62 \% \text { reduction in diarrhea and } 46 \% \\
\text { reduction in malaria among participants six months } \\
\text { after the program. The program reported a } 2 \% \\
\text { absenteeism of teachers affiliated with the program } \\
\text { as compared to } 25 \% \text { average teacher absenteeism in } \\
\text { the country. }\end{array}$ & $\begin{array}{l}\text { - Engagement of multiple stakeholders } \\
\text { ensures program effectiveness } \\
\text { - Engagement of officials boosts ownership } \\
\text { and sustainability of the program } \\
\text { - Ongoing support for facilitators ensures } \\
\text { sustainability and quality assurance of the } \\
\text { program } \\
\text { - Including topics of interest to parents in } \\
\text { workshop content supports sustained } \\
\text { parent engagement }\end{array}$ \\
\hline Little Ripples & Workshop & iACT staff & $\begin{array}{l}\text { Mothers/careg } \\
\text { ivers }\end{array}$ & $\begin{array}{l}\text { Adaptable to } \\
\text { local context }\end{array}$ & $\begin{array}{l}\text { Places emphasis on } \\
\text { activities and } \\
\text { structure that promote } \\
\text { social-emotional and } \\
\text { play-based learning }\end{array}$ & $\begin{array}{l}\text { The number of students able to name colors increased } \\
\text { from } 27 \% \text { to } 51 \% \text {, (ii) the number of students able to } \\
\text { count to five or higher increased from } 43 \% \text { to } 73 \% \text {, (iii) } \\
\text { the number of students able to identify four or more } \\
\text { animals from pictures increased from } 21 \% \text { to } 63 \% \text { and } \\
\text { (iv) the number of students able to recite at least the first } \\
\text { ten letters of the alphabet with no mistakes increased from } \\
45 \% \text { to } 83 \% \text {. }\end{array}$ & $\begin{array}{l}\text { - Allowing parents/community members } \\
\text { leadership/management of the program } \\
\text { - Adapting the program according to the } \\
\text { availability of space } \\
\text { - Focusing on quality of programming } \\
\text { rather than number of children reached } \\
\text { may allow a program to start small and } \\
\text { refine prior to scaling up. }\end{array}$ \\
\hline $\begin{array}{l}\text { Emergent } \\
\text { Literacy and } \\
\text { Math Initiative }\end{array}$ & Workshop & $\begin{array}{l}\text { Save the } \\
\text { Children/local } \\
\text { partner staff }\end{array}$ & Parents & $\begin{array}{l}8 \text { sessions } \\
\text { along the } \\
\text { course of } 4 \\
\text { months }\end{array}$ & $\begin{array}{l}\text { To increase the early } \\
\text { literacy and numeracy } \\
\text { skills of students }\end{array}$ & $\begin{array}{l}\text { children in the ELMI Centre and ELMI Parenting } \\
\text { groups showed significantly higher scores at endline on } \\
\text { both literacy and math compared to children in the Non- } \\
\text { Early Childhood Care and Development (ECCD) control } \\
\text { group, (ii) ELMI parenting children started off lowest } \\
\text { across all groups on all areas at baseline and over time } \\
\text { caught up almost entirely with their ELMI ECCD peers, } \\
\text { closing the gap from baseline and (iii) not only do the } \\
\text { ELMI Centre and Parenting programs produce strong } \\
\text { learning gains on average, but these interventions are } \\
\text { helping all families and children equally, irrespective of } \\
\text { socioeconomic status }\end{array}$ & $\begin{array}{l}\text { - Parents can be supported to learn about } \\
\text { simple, practical learning activities in and } \\
\text { around the house to engage in with their } \\
\text { child } \\
\text { - Parents may be taught simple games that } \\
\text { they can play with their children to } \\
\text { support literacy and numeracy skill } \\
\text { development } \\
\text { - The presence of print material in the } \\
\text { child's learning environment is associated } \\
\text { with gains in literacy and numeracy skills. }\end{array}$ \\
\hline $\begin{array}{l}\text { Mother Child } \\
\text { Education } \\
\text { Program } \\
\end{array}$ & Workshop & $\begin{array}{l}\text { Organization } \\
\text { staff }\end{array}$ & $\begin{array}{l}\text { Mothers/careg } \\
\text { ivers }\end{array}$ & $\begin{array}{l}25 \text { sessions; } \\
\text { once per week }\end{array}$ & $\begin{array}{l}\text { to boost school } \\
\text { readiness and optimal } \\
\text { socio-emotional }\end{array}$ & $\begin{array}{l}\text { Studies have found that with MOCEP children are better } \\
\text { equipped for school, show lower drop-out rates and } \\
\text { consequent success in education resulting in better life }\end{array}$ & $\begin{array}{l}\text { - } 25 \text { weeklong, low-cost home-based } \\
\text { program for mothers }\end{array}$ \\
\hline
\end{tabular}




\begin{tabular}{|c|c|c|c|c|c|c|c|}
\hline & & & & & $\begin{array}{l}\text { development and to } \\
\text { create a safe home }\end{array}$ & $\begin{array}{l}\text { choices and results than their peers. Empowering mothers } \\
\text { guaranteed that the environment of the child is } \\
\text { permanently changed with the likelihood to promote self- } \\
\text { sustaining changes and growth. Impact has also been } \\
\text { proven on mothers as they report better relations with } \\
\text { children and spouses as a result of positive parenting, } \\
\text { self-esteem and improved communication skills. }\end{array}$ & $\begin{array}{l}\text { - Master trainers train trainers who train } \\
\text { mothers for } 25 \text { weeks } \\
\text { - Mothers use } 10-20 \text {-page booklet each } \\
\text { week for activities to do with child } \\
\text { - Cognitive and fine motor skills } \\
\text { - Strong process monitoring }\end{array}$ \\
\hline $\begin{array}{l}\text { Parents Make } \\
\text { the Difference }\end{array}$ & & IRC staff & $\begin{array}{l}\text { Parents/caregi } \\
\text { vers }\end{array}$ & $\begin{array}{l}10 \text { sessions; } 2 \\
\text { hours each; } \\
\text { once per week }\end{array}$ & $\begin{array}{l}\text { negative effects of } \\
\text { physical and } \\
\text { psychological } \\
\text { punishment and } \\
\text { alternatives to harsh } \\
\text { punishment; positive } \\
\text { parenting skills; how } \\
\text { to promote children's } \\
\text { numeracy, } \\
\text { vocabulary, and } \\
\text { communication skills }\end{array}$ & $\begin{array}{l}\text { Evaluation found that the intervention was reasonable and } \\
\text { acceptable in this low-resource, post conflict setting, } \\
\text { significantly lowered the use of strict physical and } \\
\text { psychological punishment and significantly increased } \\
\text { caregivers' use of positive behavior management } \\
\text { practices and enhanced the quality of caregiver-child } \\
\text { relationships. However, the intervention did not have a } \\
\text { noteworthy impact on children's cognitive, emotional, or } \\
\text { behavioral outcomes. }\end{array}$ & $\begin{array}{l}\text { - Positive parenting } \\
\text { - Addressing specific health concern } \\
\text { - No sig. impact on child outcomes }\end{array}$ \\
\hline $\begin{array}{l}\text { Literacy Boost } \\
\text { Community } \\
\text { Action }\end{array}$ & Workshop & $\begin{array}{l}\text { Save the } \\
\text { Children/local } \\
\text { partner staff }\end{array}$ & $\begin{array}{l}\text { Parents/comm } \\
\text { unity } \\
\text { members }\end{array}$ & $\begin{array}{l}10 \text { sessions; } 1.5 \\
\text { hours each }\end{array}$ & $\begin{array}{l}\text { To build early literacy } \\
\text { skills and promote } \\
\text { reading and school } \\
\text { readiness }\end{array}$ & $\begin{array}{l}\text { The RCT found that involving families and communities } \\
\text { created a greater number of readers who read fluently } \\
\text { and with comprehension than simply training teachers } \\
\text { alone (Friedlander \& Goldenberg, 2016). Overall, } \\
\text { combining teacher training with community action, had } \\
\text { a larger observable impact than teacher training alone. } \\
\text { Moreover, two years of treatment had a higher impact } \\
\text { than one year alone }\end{array}$ & $\begin{array}{l}\text { - Parent sessions timing and location should } \\
\text { consider parent schedules } \\
\text { - Locally available material may be } \\
\text { resourced to make simple teaching and } \\
\text { learning materials for the home } \\
\text { - Parents may be supported to create } \\
\text { learning spaces for children in their } \\
\text { homes } \\
\text { - Parent workshops may be supplemented } \\
\text { with child-focused sessions in } \\
\text { communities } \\
\text { - Local youth may be incentivized to } \\
\text { facilitate parent sessions } \\
\text { - A combination of direct instruction, } \\
\text { modeling, hands on practice and role-play } \\
\text { is helpful }\end{array}$ \\
\hline First Steps & $\begin{array}{l}\text { Workshop/ } \\
\text { Home visits }\end{array}$ & $\begin{array}{l}\text { Community } \\
\text { trained } \\
\text { volunteers }\end{array}$ & $\begin{array}{l}\text { Parents/caregi } \\
\text { vers }\end{array}$ & $\begin{array}{l}17 \text { sessions; } 75 \\
\text { minutes each }\end{array}$ & $\begin{array}{l}\text { Focus on responsive } \\
\text { caring, playful } \\
\text { learning, language \& } \\
\text { literacy, and health } \\
\text { beginnings }\end{array}$ & $\begin{array}{l}\text { A randomized controlled trial of the pilot phase of First } \\
\text { Steps in Rwanda found: (i) improved child health and } \\
\text { nutrition practices, (ii) improved parent-child } \\
\text { engagement and (iii) increase in children reaching } \\
\text { appropriate developmental milestones following } \\
\text { programming. }\end{array}$ & $\begin{array}{l}\text { - Radio broadcast to facilitate in person } \\
\text { discussions can help to increase reach and } \\
\text { ensure uniformity across groups in } \\
\text { different locations; may be an important } \\
\text { consideration when social distancing } \\
\text { measures are required } \\
\text { - Parent workshops can offer a potential } \\
\text { space for book borrowing } \\
\text { - Home visits can supplement parent } \\
\text { sessions, particularly for families with } \\
\text { greater need } \\
\text { - Take home cards/leaflets may help } \\
\text { parents to practice activities discussed in } \\
\text { sessions at their homes }\end{array}$ \\
\hline
\end{tabular}




\begin{tabular}{|c|c|c|c|c|c|c|c|}
\hline & & & & & & & $\begin{array}{l}\text { - Children attending sessions with parents } \\
\text { allows for practice of activities discussed }\end{array}$ \\
\hline $\begin{array}{l}\text { Rise up and } \\
\text { Learn }\end{array}$ & Home visits & $\begin{array}{l}\text { Community } \\
\text { members } \\
\text { trained as home } \\
\text { visitors }\end{array}$ & $\begin{array}{l}\text { Parents/caregi } \\
\text { vers and their } \\
\text { children }\end{array}$ & $\begin{array}{l}\text { Weekly or } \\
\text { biweekly } \\
\text { visits/sessions }\end{array}$ & $\begin{array}{l}\text { Model and encourage } \\
\text { practice of positive } \\
\text { parent child } \\
\text { interaction around on } \\
\text { learning activities }\end{array}$ & $\begin{array}{l}\text { Program alleviated caregiver stress and allowed for } \\
\text { collaborative learning, opening up opportunities } \\
\text { for children to interact more with their caregivers. } \\
\text { There is also evidence that children are learning to } \\
\text { differentiate shapes, animals and colors as well as } \\
\text { engage more generally with activities through this } \\
\text { program. }\end{array}$ & $\begin{array}{l}\text { - In addition to providing skills to } \\
\text { parents, it is important to build parent } \\
\text { self-efficacy to have positive and } \\
\text { healthy interactions with their young } \\
\text { children } \\
\text { - Modeling activities for parents, in } \\
\text { their homes, and providing praise to } \\
\text { both parent and child as they engage } \\
\text { in the activity helps to build a } \\
\text { comfortable 'whole family' approach } \\
\text { - Home visits can complement other } \\
\text { activities (such as edutainment) to } \\
\text { provide direct guidance and support } \\
\text { to parents and caregivers and } \\
\text { encourage practice of learning } \\
\text { activities in the home }\end{array}$ \\
\hline
\end{tabular}




\section{Key considerations for designing a preprimary parenting program in South Sudan}

As mentioned earlier on in this review, parents need to be involved when targeting child development because their sensitive responsiveness is vital in securing attachment and its multiple consequences. Additionally, when children are at risk for poor language and cognitive development, opportunities for stimulation and learning must be created at home especially if the child does not attend preschool (Aboud, 2006). While South Sudan is among the countries with the lowest literacy levels in the world, creative solutions to engage parents and other caregivers is imperative (Malik, 2019). Programs mentioned in this review are evidence-based examples where parents have contributed effectively to their child's growth and skills. The reviewed programs highlighted key considerations to use in the South Sudanese context including: (i) low cost of implementation, (ii) use of local resources, (iii) creation of contextually relevant curriculum, (iv) supporting parents who do not know how to read/write and (v) evidence of benefits following empirical testing.

Based on the materials reviewed and programs explored for this literature review, the following are key considerations for the preparation of the South Sudan preprimary parenting program:

\section{Determine the clear objectives of the parenting program.}

As a first step, it must be determined by MoGEI and key stakeholders what the specific objective of the parent engagement program will be as this will have implications for not only the content but also the frequency and duration of the program. For instance, these features will differ if the aim is simply to increase parent awareness around the importance of the childhood development and engagement in the early years, to support certain positive parenting practices within communities, or to impact children's school readiness skills. The objective must be determined by MoGEI in close engagement with key stakeholders including local education authorities, community leaders, parents, teachers and organizations working with young children in South Sudan.

\section{Leverage existing local knowledge, beliefs, structures and activities.}

As evidenced by each of the programs reviewed in this document, a deep understanding of the local beliefs and practices around early caregiving will be required as the program is being developed. The Little Ripples program reviewed in this document provides a strong example of local input into program adaptation. A participatory approach will help the program to build upon existing cultural and parenting strengths, support ownership in a respectful and effective manner, and support parents.

Success and sustainability will rely heavily on using what is locally available and already being used. This is why qualitative exploration of the situation on the ground (through observations, KIIs, FGDs and engagement with CSOs working in pre-primary) will be key in designing specific content of the workshops including where and when they should take place, what materials can be used to create which types of toys, what can be used to create literacy material (sticks, leaves, sand, stones, etc.) which songs, stories and images may be used as examples in the sessions. Using locally available resources to create materials for the workshop along with creating games/songs that take into consideration existing cultural activities will make the workshop more relevant to the participants.

Bearing this in mind, it is essential that prior to designing the parenting program for South Sudan, an indepth qualitative study be conducted that provides insight into the lived experience of young children and their families in that context. Content of programs reviewed for this document indicate that questions included in qualitative study of the context should explore the frequency and duration of time young 
children spend with each of their parents, types of interactions they have with their parents, availability of toys and print materials in the home, typical level and nature of engagement with those toys and materials, behavior management strategies used by parents, self-efficacy of parents to care for their young children, parent knowledge about early childhood development, nutrition, health and hygiene practices, parent attitudes and behaviors regarding play and children's physical, cognitive, socio-emotional status. The information gathered from this study will not only provide important information regarding parenting of young children in South Sudan, but also inform specifics of the program designed to encourage parent engagement.

\section{Consider program content options}

The content of the program will be driven by the main objective(s) of the program and may be aligned with the preprimary curriculum of South Sudan. The programs reviewed in this document included a range of topics aimed at a range of objectives (raising awareness to changing parent behavior to impacting child learning and skill development).

The three curricula that are most often used to inform the design of parenting programs in devel oping countries are: (i) the Reach Up model based on the Jamaica home visiting program, which teaches parents how to engage their children in activities to promote cognitive stimulation; (ii) the Care for Child Development model designed by WHO and UNICEF to guide health workers and community level to provide parents with information and knowledge about cognitive stimulation and socioemotional support to their children; and (iii) the Learning Through Play model developed in Canada to train parents with low levels of education on children's physical and mental development.

Generally, topics presented to parents included early childhood development (physical, cognitive, social and emotional), health, hygiene and nutrition, (including prevention of commonly occurring illnesses), play based learning, positive discipline, positive parenting, mindfulness, promoting early literacy and numeracy skills, making teaching and learning materials (toys and books) for children at home, supporting socioemotional development of young children. In one case, topics also included those of interest to parents themselves (such as financial management). In a couple of cases, parents were provided with take-home material (such as booklets) to highlight content discussed in the sessions and/or practice activities at home with children. Annex 1 and Annex 2 provide a sample outline of general session content topics. However, detailed discussion with MoGEI and key stakeholders will be required to finalize the content of the parenting program.

\section{Consider delivery modality options}

Once the objective(s) of the parenting program are clear, the mode of delivery that is best suited to the context of South Sudan should be established. This review provides some key considerations for the decision around mode of delivery.

- Session Format. Group workshops are seen to be successful in fostering an environment of learning as it allows parents to discuss lessons learned, ask questions and share experiences which can enrich the outcome of the program and their personal experiences with the workshop. Each of the programs reviewed in this document employed a parent workshop format. In some cases, these sessions were supplemented with home visits for extra support.

- Session facilitators. Most of the programs reviewed employed community volunteers as facilitators of the parent sessions. These volunteers were often parents and in one case local youth who were trained by local staff or preprimary teachers in the region. In one case (Lively Minds) district level education officials were also indirectly involved in the process of facilitation. Having community volunteers facilitates the parenting sessions seems to foster local ownership and hence 
sustainability of the program. In one case (Little Ripples) eventually had complete management of the program. If community volunteers are used to deliver session content, it would be important to understand ways in which local volunteers may be incentivized to participate and continue to engage long term.

- Frequency and duration of session. The parenting programs reviewed ranged in duration from 8 to 25 sessions and from 1.5 to 2 hours in duration, with each program indicating significant impact on parents. For the context of South Sudan, this review suggests an approach similar to the Little Ripples program where information about the local context and availability of resources determines the frequency and duration of sessions.

- Peer learning opportunities. The review of parenting programs in this document indicates that it is important that the sessions, though facilitated, provide a space for parents to exchange information, experiences and ideas. Each session should include pair or small group work that can be shared with the larger group and all caregivers should be able to ask questions freely. In addition to having time and space for parents to exchange ideas within parent sessions, one program reviewed indicated that parents created their own parent support groups to continue discussion and experience sharing independently.

- Engagement of children. Evidence points to the fact that an intergenerational approach, where parents and children attend sessions together, if appropriate, leads to greater impact. During training sessions program facilitators can model how to play and learn together with children (UNICEF, 2016). In Rwanda's First Step and Early Literacy and Math sessions, children accompanied parents during the sessions. This was very helpful because parents could then practice games, playing with the toys, or different activities in the session as well as continue to practice at home.

- Creation and exploration. Review of programs in this document suggest that ideally, parent sessions should allow parents to create (toy, literacy material) or explore (practice what is learned with their child) either in the session or as "homework" to be discussed in the next session. Parents may be allowed to take home any materials they create to use with their children at home.

- Role playing. Programs reviewed indicate that role playing is an effective activity to incorporate into workshop sessions. Parents enjoy role playing and this serves as a basis for discussing ideas around current and desired behaviors. Different parents should be allowed to take turns role playing during the sessions.

\section{Explore cross-sectoral collaboration}

Collaboration between education, child protection and health sectors within projects is essential to program success. It is important to maintain communication and share learning across sectors and leverage strengths in individual programing towards supporting the development of young children and their families. Education teams should communicate with members in social protection and health teams to explore points of collaboration including health and hygiene efforts as well as household-based support such as cash transfers. In many cases, home visits may be built into a health or social protection program and this can be leveraged for parent engagement.

\section{Include psychosocial support for parents and children}

In addition to children, parents often carry the trauma of conflict or crisis with them and this may impact their engagement with other relatives or children in the home. While there are many different types of stress 
that could affect young children, the impact of "toxic stress" is one that needs to be considered during the design of the parenting program. Toxic stress can be of two types; (i) prolonged stress response activation and (ii) absence of protective relationships. These two factors can severely impact both young children and parents/caregivers (Steinbuchel \& Long, 2020). Research shows that children who experience adverse childhood experiences are 32 times more likely to have learning and behavioral difficulties. In the context of South Sudan, these effects could be exacerbated due to the severe impacts of COVID-19 (Steinbuchel \& Long, 2020). One must consider that while designing parenting programs in FCV contexts such as South Sudan, material resources are not enough to aid with dealing with trauma and it will be important to consider how education programs can aid with teaching the importance of creating "safe spaces" where both young children and their parents/caregivers can flourish (Steinbuchel \& Long, 2020). By providing a routine and enhancing positive interactions within the family, parenting programs, particularly in FCV contexts, provide an opportunity to support the psychosocial well-being of both parents as well as children.

\section{Provide ongoing support to facilitators and feedback to parent participants.} This review indicates that parents should have access to ongoing support through coaching and mentoring during the implementation period. By providing ample opportunities for the parents to practice and improve their skills while receiving timely feedback through supportive supervision, there is greater likelihood to improve the quality of the program and produce intended outcomes.

Similarly, facilitators, especially those who are community volunteers, stand to benefit from ongoing support and encouragement in running workshop sessions. This will be an important feature to consider in the design of the program for South Sudan. Considerations for facilitators should include training and supportive supervision ${ }^{5}$.

- Training: Facilitators of any parenting intervention should be trained through hands-on, learning methodologies (including role playing) that will facilitate application with parents and caregivers. The duration of the training depends on the curriculum adapted/developed for the intervention but is usually a minimum of 4 days training at 6-8 hours per day. Project design should include inservice refresher training on identified skills that have been found through supportive supervision activities to be challenging for the facilitators.

- Supportive Supervision: After training, supportive supervision provides mentoring and coaching to monitor and deepen the skills introduced during training. This is done through observation and feedback as well as opportunities for reflection

\section{Start small and remain flexible.}

One of the key learning from Little Ripples programming mentioned by iACT is the maintaining the focus on quality of programming rather than number of children reached. Given that this will be the first parent engagement program designed specifically for the context of South Sudan, iACT's learning will be especially pertinent in this context and should be considered as such. Further, given that the context of South Sudan and hence the lives of parents and children in South Sudan is unpredictable, programming should build in flexibility to adapt to changing situations on the ground.

\footnotetext{
${ }^{5}$ For more information on this topic: https://www.earlychildhoodworkforce.org/Early-Childhood-Resources
} 


\section{Keep an eye towards program scalability.}

Although the current review is meant to inform the design of a small-scale pilot intervention, if positive benefits are seen for parents and children in South Sudan, the next step would be scaling up of the program. As such, developers of the program should bear in mind challenges that may inhibit scaling up of the program and build in mitigation measures into the design early on. This may include a strong communication strategy to ensure stakeholder buy-in as well as innovative strategies to build local ownership and sustainability of the program.

\section{Additional important considerations}

- Consider engaging youth. In Rwanda, the national youth volunteering program requires every secondary school graduate to volunteer in their community in different ways. Those who performed very well in school could apply to be parent workshop facilitators. They were trained on Literacy Boost Community Action sessions by Save the Children's local partner Umuhuza and pairs of two facilitators led the workshops in their own village. This was an empowering experience for the youth, their familiarity with the families encouraged participation and sustainability and the parents/young children appreciated seeing their own youth in those leadership roles. This may be an interesting and valuable aspect to explore in the context of South Sudan. Qualitative study should explore this possibility.

- Explore how to maximize engagement of fathers. All of the programs studies in this review indicated stronger participation of mothers in the parent programs than fathers. For various reasons, engagement of fathers, especially in the lives of young children, remains lower than mothers. Some programs, such as First Steps in Rwanda, have explored innovative ways to engage fathers in children's early learning activities with their children. This is an important avenue to explore as the program for South Sudan is being designed. 


\section{Covid-19 and delivery modality considerations}

Now, more than ever, parents and caregivers have a pivotal role to play at the front lines of protecting their children from stress and promoting their development, health, and well-being. Research shows that children who experience adverse childhood experiences are 32 times more likely to have learning and behavioral difficulties and in the context of South Sudan, these effects could be exacerbated due to the severe impacts of COVID-19 (Steinbuchel \& Long, 2020). Due to the uncertain nature of COVID-19, considerations on how to incorporate activities in a safe environment will be necessary. The qualitative study along with the implementation of the parenting workshop will require precautionary steps to ensure that both participants and facilitators are safe.

While parenting programs can be delivered in a multitude of ways, the most relevant for the case of South Sudan seems to be the group session format. However, given social distances measures, it is unclear whether this format will be feasible in the near future at the time of this review. As such, the review recommends exploring the option of using technology (using radio and or mobile phones) to deliver key content to parents/caregivers of young children in South Sudan.

Radio broadcast. In light of the current social distancing efforts underway globally (including South Sudan), community gathering of parents may be unsafe. In this case, radio broadcast of session content seems to be the best option. The Ministry of General Instruction and Education has already begun to provide interactive radio instruction through national radio broadcast in South Sudan. The same mechanism may be explored to provide messages around positive parenting practices, as well as maintaining health and hygiene in the homes of young children. The experience of First Steps in Rwanda may offer learning for the best way to deliver parenting content via radio. First Steps program in Rwanda centered their parenting workshops around local radio station. So, at the time the workshops were meant to meet, the radio station would play a short entertaining scene related to the days topic and then ask questions. The group listened to the radio broadcast then use what was heard as a starting point for discussion.

Mobile phones. Another option may be to transmit the messages to facilitators via cell phones or provide facilitators with phones loaded with recordings to play at the beginning of each session.

\section{Next Steps}

As indicated by this review, it will be important to have a clear picture of the lived experience of young children, their families and communities in South Sudan prior to designing a program that is relevant and appropriately meets their needs.

This will include an understanding of the local customs and traditions used in caregiving of the youngest children (such as which songs, stories and games are commonly shared), how much interaction fathers and mothers have with their young children, when the engagement occurs and the nature of engagement, resources readily available on the ground to use in teaching and learning (e.g. sticks, rocks, plants, fabric), daily activities of families (to ascertain moments and activities that lend themselves to teaching and learning), local perceptions around child development and early parenting, teaching and learning, and caregivers perceptions around key opportunities and challenges in supporting children's cognitive, physical and socio-emotional skills and school readiness. As such, qualitative inquiry into these features of life in South Sudan is essential before an effective program may be developed. 
A key next step should involve the design of focus group discussion and key informant interview questions and protocols for the qualitative study. Information gathered in this review may serve as a guide in determining those questions and protocols. 


\section{References}

Aboud, F. E. (2006). Evaluation of an early childhood preschool program in rural Bangladesh. Early Childhood Research Quarterly, 21(1), 46-60.

Aboud, F. E., \& Akhter, S. (2011). A cluster-randomized evaluation of a responsive stimulation and feeding intervention in Bangladesh. Pediatrics, 127(5), e1191-e1197.

ACEV; Mother Child Education Foundation. (2019). Available: https://www.acev.org/en/

Additional years of schooling calculated using methodology found in Evans, David K. and Fei Yuan. 2018. "Equivalent Years of Schooling: A Metric to Communicate Learning Gains in Concrete Terms." World Bank Policy Research Working Paper 8752.

Al-Hassan, S. M., \& Lansford, J. E. (2011). Evaluation of the better parenting programme in Jordan. Early child development and care, 181(5), 587-598.

Allen, S., \& Daly, K. (2002). The effects of father involvement: A summary of the research evidence. The FII-ONews, 1(1-11). Retrieved from http://www.fira.ca/cms/documents/29/Effects_of_Father_Involvement.pdf

Amadu, S., Attanasio, O. P., Caeyers, B., Cattan, S., Sosa, L. C., Krutikova, S., \& Yakubu, M. (2018). Improving early childhood development in rural Ghana through scalable low-cost community-run play schemes: Baseline report (No. R144). IFS Report.

Amente, A., Yenew, A., Borisova, I., Dowd, A. J., Pisani, L., Dang, S., \& Anís, K. (2017). Save the Children's Emergent Literacy and Mathematics Initiative: Supporting Educators' and Parents' Efforts to Improve Young Children's School Readiness. YC Young Children, 72(4), 31-34.

Bouchane, K., Yoshikawa, H., Murphy, K. M., \& Lombardi, J. (2019). Early Childhood Development and Early Learning for Children in Crisis and Conflict. Paper commissioned for the 2019 Global Education Monitoring Report, Migration, displacement and education: Building bridges, not walls, UNESCO, Paris. Available at bitly.com/2019gemreport.

Burde, D., Guven, O., Kelcey, J., Lahmann, H., \& Al-Abbadi, K. (2015). What works to promote children's educational access, quality of learning, and wellbeing in crisis-affected contexts. Education Rigorous Literature Review, Department for International Development. London: Department for International Development.

Chazan-Cohen, R., Raikes, H., Brooks-Gunn, J., Ayoub, C., Pan, B. A., Kisker, E. E., \& Fuligni, A. S. (2009). Low-income children's school readiness: Parent contributions over the first five years. Early Education and Development, 20(6), 958-977.

Cost effectiveness analysis (CEA) conducted by IPA according to the methodology found in Dhaliwal, I., Duflo, E., Glennerster, R., and Tulloch, C. 2012. "Comparative Cost-Effectiveness Analysis to Inform Policy in Developing Countries: A General Framework with Applications for Education." Abdul Latif Jameel Poverty Action Lab (J-PAL), MIT. CEA does not include opportunity costs of time spent by mothers or teachers on the Lively Minds program. 
Crain-Thoreson, C., \& Dale, P. S. (1992). Do early talkers become early readers? Linguistic precocity, preschool language, and emergent literacy. Developmental Psychology, 28, 421. doi: 10.1037/0012-1649.28.3.421.

Dallain, Sara-Christine, and Katie-Jay Scott. (2017). LITTLE RIPPLES: Refugee-led early childhood education.

Available: https://static1.squarespace.com/static/583af1fb414fb5b3977b6f89/t/59bdb9c703596e9e8b02d5b8 /1505606090047/6 PromisingPractices iACT WEB.pdf

Desforges, C. \& Abouchaar, A. (2003). The impact of parental involvement, parental support and family education on pupil achievement and adjustment: A literature review. London: UK. Queens Publishing.

Dhaliwal, I., Duflo, E., Glennerster, R., \& Tulloch, C. (2013). Comparative cost-effectiveness analysis to inform policy in developing countries: a general framework with applications for education. Education policy in developing countries, 285-338.

Dickinson, D. K., \& Tabors, P. O. (1991). Early literacy: Linkages between home, school and literacy achievement at age five. Journal of Research in Childhood Education, 6, 30-46. doi:10.1080/02568549109594820

Early Childhood Peace Consortium (ECPC). (2018). Contributions of Early Childhood Development Programming to Sustainable Peace and Development. New York: Early Childhood Peace Consortium. Available from https://ecdpeace.org/ecpc-background-paper

Epstein, J. L., \& Sheldon, S. B. (2006). Moving forward: Ideas for research on school, family, and community partnerships. SAGE handbook for research in education: Engaging ideas and enriching inquiry, 117-138.

Evans, D. K., \& Yuan, F. (2018). The working conditions of teachers in low-and middle-income countries. World Bank 2018 World Report.

Friedlander, E. \& Goldenberg, C. (eds.). (2016). Literacy Boost in Rwanda: Impact Evaluation of a 2-year Randomized Control Trial. Stanford, CA: Stanford University

Galindo, C., \& Sheldon, S. B. (2012). School and home connections and children's kindergarten achievement gains: The mediating role of family involvement. Early Childhood Research Quarterly, 27(1), 90-103.

Gertler, P., Heckman, J., Pinto, R., Zanolini, A., Vermeerch, C., Walker, S., ... \& Grantham-McGregor, S. (2013). Labor market returns to early childhood stimulation: A 20-year follow-up to an experimental intervention in Jamaica. The World Bank.

Ghana Statistical Service, Ghana Health Service, and ICF International. 2015. "Ghana Demographic and Health Survey 2014.” https://dhsprogram. com/pubs/pdf/fr307/fr307.pdf 
Giusto, A., Friis, E., Sim, A. L., Chase, R. M., Zayzay, J. O., Green, E., \& Puffer, E. (2017). A qualitative study of mechanisms underlying effects of a parenting intervention in rural Liberia. The European Journal of Development Research, 29(5), 964-982.

Grantham-Mcgregor, S. \& Walker, S. (2015). The Jamaican early childhood home visiting intervention. Early Childhood Matters. Available: https://bernardvanleer.org/ecm-article/2015/the-jamaicanearly-childhood-home-visiting-intervention/

Hart, B., \& Risley, T. R. (1995). Meaningful differences in the everyday experience of young American children. Paul H Brookes Publishing.

Hassinger-Das, B., Hirsh-Pasek, K., \& Michnick Golinkoff, R. (2017). The Case of Brain Sci-ence and Guided Play: A Developing Story. [Young Children, Vol. 72 No. 2]. Retrieved from http://www.naeyc.org/yc/article/case-brain-science-guided-play

Henderson, A. T., \& Mapp, K. L. (2002). A New Wave of Evidence: The Impact of School, Family, and Community Connections on Student Achievement. Annual Synthesis, 2002.

Hess, R. D., Holloway, S. D., Dickson, W. P., \& Price, G. G. (1984). Maternal variables as predictors of children's school readiness and later achievement in vocabulary and mathematics in sixth grade. Child Development, 55, 1902-1912. doi. 10.1111/j.1467-8624.1984.tb00432.x

Jeynes, W. H. (2005). A meta-analysis of the relation of parental involvement to urban elementary school student academic achievement. Urban education, 40(3), 237-269.

Kagitcibasi, C., Sunar, D., \& Bekman, S. (2001). Long-term effects of early intervention: Turkish lowincome mothers and children. Journal of Applied Developmental Psychology, 22(4), 333-361.

Kraft, M. 2018. "Interpreting Effect Sizes of Education Interventions". Working Paper. Available on: https://scholar.harvard.edu/files/mkraft/files/ kraft_2018_interpreting_effect_sizes.pdf

Little Ripples Teacher Training: Mindfulness. Available: https://vimeo.com/219133046. (Accessed: 12 April 2020).

Lonigan, C. J., Dyer, S. M., \& Anthony, J. L. (1996, April). The influence of the home literacy environment on the development of literacy skills in children from diverse racial and economic backgrounds. Paper presented at the Annual Meeting of the American Educational Research Association; New York.

Malik, S. (2018). Advancing the Right to Read in Rwanda: Final evaluation. Save the Children International.

Malik, S. (2019). Preprimary Education in South Sudan; Current Opportunities and Challenges. World Bank.

NICHD Early Child Care Research Network The effects of infant child care on infant-mother attachment security. Child Dev. 1997;68:860-79

Nye, C., Turner, H., \& Schwartz, J. (2006). Approaches to parent involvement for improving the academic performance of elementary school age children. Campbell Systematic Reviews, 2(1), 1-49.1 
Park, H. (2008). Home literacy environments and children's reading performance: A comparative study of 25 countries. Educational Research and Evaluation, 14, 489-505.

doi:10.1080/13803610802576734

Payne, A. C., Whitehurst, G. J., \& Angell, A. L. (1994). The role of home literacy environment in the development of language ability in preschool children from low-income

Reese, E., Sparks, A., \& Leyva, D. (2010). A review of parent interventions for preschool children's language and emergent literacy. Journal of Early Childhood Literacy, 10(1), 97-117.

Roopnarine, J. L., \& Krishnakumar, A. (2006). Parent-child and child-child play in diverse cultural contexts. Play from birth to twelve: Contexts, perspectives, and meanings, 275-288.

Save the Children. "Literacy Boost Toolkit". (2012). Available: https://www.savethechildren.org/content/dam/global/reports/education-and-child-protection/litbst-toolkit-intro.pdf

Save the Children. "Early Literacy and Math Initiative, Rwanda Endline Report". (2015). Available:https://resourcecentre.savethechildren.net/node/9137/pdf/rwanda_elmi_endline_report_ final.pdf

Save the Children (2016). Saving Brains. First Steps 0-3 Program in Rwanda Endline Report. Available: https://resourcecentre.savethechildren.net/library/saving-brains-first-steps-0-3-program-rwandaendline-report

Save the Children (2010a). Mozambique Literacy Boost 2010 report. Washington, DC: Save the Children U.S.

Save the Children (2010b). Malawi Literacy Boost 2009: Year 1 report. Washington, DC: Save the Children U.S.

Save the Children (2011). Literacy Boost Pakistan: Year 1 report. Washington, DC: Save the Children U.S.

Save the Children (2012). Literacy Boost toolkit: Community action component. Washington, DC: Save The Children U.S.

Sénéchal, M., LeFevre, J. A., Hudson, E., \& Lawson, E. P. (1996). Knowledge of storybooks as a predictor of young children's vocabulary. Journal of Educational Psychology, 88, 520-536. doi:10.1037/0022-0663.88.3.520

Sesame Workshop. “Ahlan Simsim”. (2019). Available: https://www.sesameworkshop.org/what-wedo/shows/ahlan-simsim

Sim, A. (2014). Parents Make the Difference; IRC brief. Available: https://www.rescue.org/sites/default/files/document/705/parentsmakedifferencebrieffinal18nov14 .pdf 
Singer, D., Golinkoff, R. M., \& Hirsh-Pasek, K. (2006). Play= Learning: How play motivates and enhances children's cognitive and social-emotional growth. Oxford University Press.

Snow, C. E., Burns, S. M., \& Griffin, P. (1998). Predictors of success and failure in reading. Preventing reading difficulties in young children, 100-134.

Sonnenschein, S., Baker, L., Serpell, R., Scher, D., Truitt, V. G., \& Munsterman, K. (1997). Parental beliefs about ways to help children learn to read: The impact of an entertainment or a skills perception. Early Child Development and Care, 127, 111-118. doi:10.1080/0300443971270109

Steinbuchel, P \& Long, D. (2020). Addressing adversity and promoting resilience during Early Childhood. Available:https://worldbankgroup.sharepoint.com/sites/Education/Lists/Calendar/Attachments/52 55/EarlyChildhoodWorldBankedit5.12.202.pdf

Thorndike, R. (1976). Reading comprehension in fifteen countries. In J. Merrit (Ed.), New horizons in reading (pp. 500-507). Newark, DE: International Reading Association.

UNICEF. "Care for Child Development: A framework for monitoring and evaluating the WHO/UNICEF intervention".

Available: https://www.unicef.org/earlychildhood/files/7._Framework_for_ME.pdf, 2012.

UNICEF. "Standards for ECD Parenting Programs in Low and Middle Income Countries". Available: https://www.unicef.org/earlychildhood/files/UNICEF-Standards_for_Parenting_Programs_6-817 _pg.pdf

Wagner, D. A., \& Spratt, J. E. (1988). Intergenerational literacy: Effects of parental literacy and attitudes on children's reading achievement in Morocco. Human Development, 31, 359-369. doi:10.1159/000276335

Wells, G. (1985). Preschool literacy-related activities and success in school. In D. Olson, N. Torrance, \& A. Hildyard (Eds.), Literacy, language, and learning: The nature and consequences of reading and writing (pp. 229-255). Cambridge, MA: Cambridge University Press.

World Bank (2018). "Promoting Early Childhood Development through combining cash transfers and parenting programs". Available: file:///Users/saima/Downloads/Promoting\%20ECD\%20through\%20Parenting\%20program\%20by \%20WB.pdf 


\section{Annex 1. South Sudan Parent Workshop Draft}

\section{Session 1: Introduction to early childhood education}

- Importance of early childhood in human development

- What is ECE and why is it important?

- Strengths and challenges of child-rearing in S. Sudanese culture

Session 2: Positive Family Positive Child

- What does positive parenting look like?

- How to create a positive environment for your child

Session 3: Nutrition

- Creating nutritious meals with resources available (demonstration)

Session 4: Health and Hygiene

- Hand washing

- Boiling water

- Vaccinations

- Medical Check-ups

- Prevention of common illness (malaria, COVID-19 19)

Session 5: Communication

- Talk and listen

- Ask and answer questions

- $\quad$ Sing songs

- Tell stories

Section 6: Peaceful children/peaceful communities

- Understanding and expressing emotion

- Mindfulness strategies

- Conflict resolution

Session 7: Books: Reading to and with children

- Creating books using locally available resources

Session 8: Importance of Play

- Sample literacy/numeracy games

- Creating toys with locally available materials 


\section{Annex 2. Sample Session Outline}

1. South Sudanese Song (5 minutes)

2. Introduction (10 minutes)

3. Radio Clip/Story/Session Hook (10 minutes)

4. Discussion in Small Groups (10 minutes)

5. Share out to large group (15 minutes)

6. Message Delivery (10 minutes)

7. Role play activity-planning and sharing (20 minutes)

8. Creation Activity (Demonstration and parent creation) using local material 25 minutes

9. Sharing of creation activity (10 minutes)

10. South Sudanese Song or Read-Aloud of South Sudanese story (5 minutes)

Total time: 2 hours 